\title{
Apparent Liquid Permeability in Mixed-Wet Shale Permeable Media
}

\author{
Dian $\operatorname{Fan}^{1}$ (I) $\cdot$ Amin Ettehadtavakkol ${ }^{2} \cdot$ Wendong Wang ${ }^{3}$
}

Received: 6 September 2019 / Accepted: 4 August 2020 / Published online: 17 August 2020

(c) The Author(s) 2020

\begin{abstract}
Apparent liquid permeability (ALP) in ultra-confined permeable media is primarily governed by the pore confinement and fluid-rock interactions. A new ALP model is required to predict the interactive effect of the above two on the flow in mixed-wet, heterogeneous nanoporous media. This study derives an ALP model and integrates the compiled results from molecular dynamics (MD) simulations, scanning electron microscopy, atomic force microscopy, and mercury injection capillary pressure. The ALP model assumes viscous forces, capillary forces, and liquid slippage in tortuous, rough pore throats. Predictions of the slippage of water and octane are validated against MD data reported in the literature. In up-scaling the proposed liquid transport model to the representative-elementary-volume scale, we integrate the geological fractals of the shale rock samples including their pore size distribution, pore throat tortuosity, and pore-surface roughness. Sensitivity results for the ALP indicate that when the pore size is below $100 \mathrm{~nm}$ pore confinement allows oil to slip in both hydrophobic and hydrophilic pores, yet it also restricts the ALP due to the restricted intrinsic permeability. The ALP reduces to the well-established Carman-Kozeny equation for no-slip viscous flow in a bundle of capillaries, which reveals a distinguishable liquid flow behavior in shales versus conventional rocks. Compared to the Klinkenberg equation, the proposed ALP model reveals an important insight into the similarities and differences between liquid versus gas flow in shales.
\end{abstract}

Keywords Apparent liquid permeability · Nanoporous media $\cdot$ Confinement effect $\cdot$ Liquid slippage $\cdot$ Carman-Kozeny equation

\section{List of Symbols \\ $d_{\mathrm{p}} \quad$ Pore diameter \\ $r_{\mathrm{p}} \quad$ Pore radius \\ $\delta_{\mathrm{w}} \quad$ Near-wall region thickness \\ $L_{\mathrm{s}} \quad$ Straight pore length}

Dian Fan

d.fan@ucl.ac.uk

1 Department of Chemical Engineering, University College London, London, UK

2 Bob L. Herd Department of Petroleum Engineering, Texas Tech University, Lubbock, TX, USA

3 School of Petroleum Engineering, China University of Petroleum (East China), Qingdao, China 
$L_{\mathrm{p}} \quad$ Tortuous pore length

$\tau \quad$ Tortuosity

$\phi \quad$ Porosity

$d_{\mathrm{m}} \quad$ Matrix grain diameter

$\alpha \quad$ Areal ratio of the conical nanostructures (roughness elements)

$\beta \quad$ Ratio of the minimum to the maximum conical base diameter

$\gamma \quad$ Pore-size heterogeneity coefficient

$\varepsilon \quad$ Relative roughness

$\alpha_{\mathrm{s}} \quad$ Fraction of the available sites for liquid migration

$\alpha^{*} \quad$ Bending angle of the tube

$\beta^{*} \quad$ Tilting angle of the tube

$D_{\mathrm{p}} \quad$ Pore size fractal dimension

$D_{\mathrm{T}} \quad$ Tortuosity fractal dimension

$D_{\mathrm{c}} \quad$ Fractal dimension of conical base size distribution

$\mu_{\mathrm{b}} \quad$ Bulk viscosity

$\mu_{\mathrm{w}} \quad$ Near-wall viscosity

$D_{\text {s }} \quad$ Surface diffusion coefficient

$W_{\mathrm{A}} \quad$ Work of adhesion

$\Delta P \quad$ Pressure difference

$Q \quad$ Volumetric flow rate

$\lambda_{\mathrm{b}} \quad$ Pore-structure factor

$\lambda_{\mathrm{s}} \quad$ Slippage factor

$l_{\text {slip }} \quad$ Slip length

\section{Subscripts \\ app Apparent \\ i Inorganic matter \\ o Organic matter}

\section{Introduction}

Flow enhancement of liquids in confined hydrophilic and hydrophobic nanotubes is often observed in experiments where the liquid flow rate is reported to be several orders of magnitude more than that predicted by the classic Hagen-Poiseuille equation (de Gennes 2002; Joseph and Aluru 2008; Myers 2011; Podolska and Zhmakin 2013; Whitby and Quirke 2007). Molecular dynamics (MD) simulations are often used to understand the fluid structure and the fast transport mechanisms under confinement (Hummer et al. 2001; Joseph and Aluru 2008; Majumder et al. 2005; Striolo 2006). Physical properties (e.g., viscosity and density) of liquid near the tube wall can be different from the bulk liquid due to liquid-solid interactions, which is found the main cause for the fast transport of both non-wetting and wetting liquids (Falk et al. 2010; Noy 2007). Fast transport of non-wetting liquid is attributed to the hydrogen bonding of the liquid, which results in the recession of liquid from the solid surface (Hummer et al. 2001), the formation of "a nearly frictionless vapor interface" between the surface and the bulk phase (Majumder et al. 2005), or fast ballistic diffusion of liquid (Striolo 2006). Fast transport of wetting liquid is attributed to the presence of excessive dissolved gas at the liquid-solid interface (de Gennes 2002) or the capability of water migrating from one adjacent adsorption site to another (Ho et al. 2011). 
In principle, MD simulations are the best tool to quantify microscopic physics, yet their computational effort can be intensive and time-consuming. Quantitative analytical models have so far been able to predict the flow enhancement of the confined liquid. The flow enhancement factor $(f)$, defined as the ratio of the measured (apparent) volumetric flow rate $\left(Q_{\text {app }}\right)$ to the intrinsic volumetric flow rate predicted by the Hagen-Poiseuille equation $(Q)$, is usually applied to evaluate flow enhancement through nanotubes. Table 1 summarizes some classical analytical models for flow enhancement. The main differences between these models are how viscosity is modeled and who is the contributor to the flow enhancement. The Tolstoi model (Tolstoi 1952), one of the earliest quantitative attempted to model liquid slippage along a capillary of radius $r$, assumes that the average liquid viscosity remains constant along the radial direction of the flow and is not affected by the wall. Thomas and McGaughey (2008) and Myers (2011) proposed the slippage model with a variable viscosity at a distance away from the wall, the approach of which, to some extent, accounts for the liquid-solid interactions (de Gennes 2002; Hummer et al. 2001; Thomas and McGaughey 2008). A schematic of such models in a confined channel or pore is illustrated in Fig. 1. Mattia and Calabrò (2012) further incorporated the surface diffusion and liquid adhesion near the wall surface, which characterizes the flow enhancement as a consequence of the migration of liquid molecules on the surface in addition to the viscous effect. The models reviewed here provide a parametrized approach for studying liquid transport in complex pore networks and, in particular, lay a theoretical basis for understanding shale oil transport.

Shale rocks are ultra-confined permeable media with a typical intrinsic permeability of less than $0.1 \mathrm{mD}$ (Fan and Ettehadtavakkol 2016, 2017a; Rezaee 2015; Song et al. 2019). The shale constituents are primarily divided into organic matter and inorganic

Table 1 Quantitative analytical models of flow enhancement

Authors Flow enhancement models

Tolstoi (1952)

$$
\begin{aligned}
& f=1+\frac{4 l_{\text {slip }}}{r} \\
& l_{\text {slip }}=\delta_{0}\left[e^{\alpha S\left(W_{1}-W_{\mathrm{ls}}\right) / k_{\mathrm{B}} T}-1\right]
\end{aligned}
$$

Thomas and McGaughey (2008)

$$
\begin{aligned}
& f=\left(1+\frac{4 l_{\text {slip }}}{r}\right) \frac{\mu_{\mathrm{b}}}{\mu(r)} \\
& \mu(r)=\mu_{\mathrm{w}} \frac{A_{\mathrm{w}}(r)}{A_{t}(r)}+\mu_{\mathrm{b}}\left[1-\frac{A_{\mathrm{w}}(r)}{A_{t}(r)}\right] \\
& l_{\text {slip }}=l_{\text {sil }, \infty}+\frac{C^{\prime}}{r^{3}}
\end{aligned}
$$

Myers (2011)

$$
\begin{aligned}
& f=1+\frac{4 l_{\text {slip }}}{r} \approx 1+\frac{4 \delta_{\mathrm{w}}}{r} \frac{\mu_{\mathrm{b}}}{\mu_{\mathrm{w}}} \\
& l_{\text {slip }}=\delta_{\mathrm{w}}\left(\frac{\mu_{\mathrm{b}}}{\mu_{\mathrm{w}}}-1\right)\left[1-\frac{3}{2} \frac{\delta_{\mathrm{w}}}{r}+\left(\frac{\delta_{\mathrm{w}}}{r}\right)^{2}-\frac{1}{4}\left(\frac{\delta_{\mathrm{w}}}{r}\right)^{3}\right]
\end{aligned}
$$

Mattia and Calabrò (2012)

$$
\begin{aligned}
& f=\left(\frac{r-\delta_{\mathrm{w}}}{r}\right)^{4}\left(1-\frac{\mu_{\mathrm{b}}}{\mu_{\mathrm{w}}}\right)+\frac{\mu_{\mathrm{b}}}{\mu_{\mathrm{w}}}\left(1+\frac{4 l_{\text {slip }}}{r}\right) \approx \frac{8 \mu_{\mathrm{b}} L}{r^{2}} \frac{D_{\mathrm{s}}}{W_{\mathrm{A}}} \\
& l_{\text {slip }}=\frac{2 \mu_{\mathrm{w}} L_{\mathrm{s}}}{r} \frac{D_{\mathrm{s}}}{W_{\mathrm{A}}}
\end{aligned}
$$

Nomenclature: $l_{\text {slip }}$ is the slip length. $\delta_{0}$ is the distance between the centers of the neighboring liquid molecules. $\delta_{\mathrm{w}}$ is the near-wall region thickness. $W_{1}$ and $W_{\mathrm{ls}}$ denote the work of adhesion of the liquid and the liquid-solid, respectively. $S$ and $\alpha_{\mathrm{s}}$ are the surface area and the fraction of the available sites for liquid migration, respectively. $\mu(r)$ is the weighted-average viscosity over the cross-sectional area fraction of the near-wall region (denoted as $A_{\mathrm{w}}$ ) and the total flow region (denoted as $A_{\mathrm{t}}$ ), where their viscosity is denoted by $\mu_{\mathrm{w}}$ and $\mu_{\mathrm{b}}$, respectively. $l_{\text {slip, } \infty}$ is the slip length of a liquid on a flat surface (without confinement). $C^{\prime}$ is a fitting parameter. $L_{\mathrm{s}}$ is the length of the nanotube (straight length) 
Fig. 1 Bulk flow and near-wall regions in a confined channel or pore

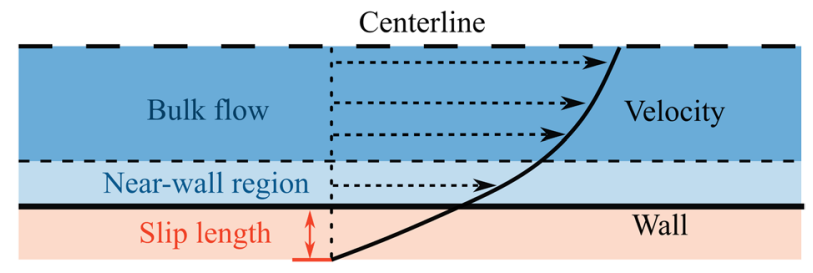

minerals each having different wettability. The presence of organic and inorganic pores induces the characteristics of mixed wettability of shales. Inorganic clay minerals, e.g., kaolinite, illite, and smectite, are usually hydrophilic, while the organic matter, e.g., kerogen and bitumen, varies from highly hydrophobic to mixed-wet based on rock thermal maturity (Rezaee 2015). Experimental study of oil and brine transport in mixedwet limestones shows that the wetting phase can slip in mixed-wet rock, and that the slip length increases with a decreasing pore size (Christensen and Tanino 2017). Recent studies attempted to model the apparent liquid permeability of shale rocks by applying the aforementioned flow enhancement models (Cui 2019; Cui et al. 2017; Fan et al. 2019a; Feng et al. 2019; Wang et al. 2019a; Wang and Cheng 2019; Yang et al. 2019; Zhang et al. 2017). Cui et al. (2017) studied liquid slippage and adsorption in hydrophobic organic pores of shales and highlighted the importance of the adsorption layer for oil flow in organic pores of size $500 \mathrm{~nm}$. Zhang et al. (2017) modeled liquid slippage in inorganic pores and liquid adsorption in organic pores and showed that the wettability difference of these two pores leads to the fact that the apparent permeability of inorganic pores can be four orders of magnitude more than that of organic pores.

Differences in pore structures of inorganic versus organic matters with regards to pore size, pore size distribution, and surface roughness, also impact transport behaviors (Fan and Ettehadtavakkol 2017a). The average size of organic pores is usually at least one order of magnitude less than that of inorganic pores. Organic pores are more uniformly distributed by size than inorganic ones, e.g., $18-438 \mathrm{~nm}$ for the former ( $\mathrm{Lu}$ et al. 2015) versus $3 \mathrm{~nm}-100 \mu \mathrm{m}$ for the latter (Chalmers et al. 2012). The surface roughness of pores is found scaled with pore sizes, e.g., the relative roughness, defined as the ratio of the roughness height divided by the local pore diameter, is often observed smaller in organic pores than inorganic ones (Javadpour et al. 2015). The impact of surface roughness on transport is complex, e.g., slippage may be reduced due to stronger hydrogen bonding on rougher surfaces (Joseph and Aluru 2008; Myers 2011) or enhanced due to the nano-scale 'lotus effect' (Cao et al. 2006).

To date, studies on liquid transport behavior especially oil in mixed-wet porous media are limited. Understanding is still insufficient on the overall impact of pore structure and liquid-solid interactions of the rock permeability at the representative-elementary-volume (REV) scale, i.e., the smallest volume of which the measured permeability and porosity are statistically representative of, e.g., the whole rock core sample. This study develops a new apparent liquid permeability (ALP) model and provides an avenue for estimating the ALP of a chemical and spatially heterogeneous, confined permeable media via integrating atomistic and core-scale data. The data include core-flooding measurements, scanning electron microscope (SEM) images, mercury injection capillary pressure (MICP) tests, lattice Boltzmann (LB) simulations, MD simulations, and atomic force microscopy (AFM) results. The proposed ALP model presents the following contributions: 
1. The ALP model quantifies liquid slippage contribution to the total flow rates on wetting and non-wetting surfaces.

2. The ALP model accounts for REV-scale heterogeneity in pore size and pore throat tortuosity, and pore-scale roughness on liquid slippage.

3. The ALP model compiles MD data readily via detailed workflows proposed in this work.

4. The ALP model clarifies the analogies and differences between the shale permeability model and classic permeability models. In particular, a critical comparative analysis between the proposed ALP model and the Carman, the Carman-Kozeny, and the Klinkenberg equations is presented to highlight the virtues and features of the ALP model.

\section{Method}

This section presents the derived liquid slippage and the ALP for heterogeneous, tortuous, rough, and mixed-wet porous media at the REV scale. The ALP combines the effect of pore structure, near-wall flow regions as well as fluid-rock interactions.

\subsection{Flow Enhancement Model}

In shale rocks, properties of near-wall regions are different in inorganic and organic pores due to wettability. In addition to "free oil," organic pores, typically hydrophobic ones, are rich in adsorbed oil (Ambrose et al. 2010). The flow in cylindrical organic pores accordingly can be divided into two viscous regions: a cylindrical bulk flow region of viscosity $\mu_{\mathrm{b}}$ and an annular near-wall region of thickness $\delta_{\mathrm{w}}$ and viscosity $\mu_{\mathrm{w}}$. The concept of this biviscosity model also applies to hydrophilic inorganic pores because the strong hydrophilicity promotes the oil slippage within such pores, rendering the viscosity near the wall lower than the bulk value (Wang et al. 2016).

Of note, the "near-wall region" here refers to as the region where the local fluid density deviates from the bulk density from the pore surface. This region should not be confused with the "depletion region (DR)," the formation of which, e.g., for water on hydrophobic surfaces, is due to the repulsive electrostatic interactions between water molecules and nonpolar surfaces, and this region typically refers to the region where the local liquid density is less than 2-5\% of the bulk density (Joseph and Aluru 2008; Farimani et al. 2016). To clarify the definition of the two regions, we present an example of water flow through carbon nanotubes (CNTs) in Fig. 2a. At the DR, water concentration decreases intensively, which corresponds to "velocity peak" and "velocity jump" in radial and axial velocity (Joseph and Aluru 2008; Shaat 2017). This region is $\sim 2 \AA$ thick, close to the value reported in the literature as one water molecule layer, i.e., $2.75 \AA$ (Doshi et al. 2005; Janeček and Netz 2007; Jensen et al. 2003; Mamatkulov et al. 2004; Sendner et al. 2009). In contrast, the "near-wall region" is much wider, e.g., $7 \AA$ (Joseph and Aluru 2008). Similar rules to identify the near-wall region and the DR also apply to the silica-octane system (Fig. 2b).

Following the methodology described by Mattia and Calabrò (2012), we derive the intrinsic volumetric flow rate $Q$ (Eq. 22) and the apparent volumetric flow rate $Q_{\text {app }}$ (Eq. 31), in which the Ruckenstein's slip (Eq. 4b) is used to account for the contribution of surface diffusion and liquid adhesion to flow enhancement. The ratio of $Q_{\text {app }}$ and $Q$ yields the flow enhancement factor (Mattia and Calabrò 2012): 

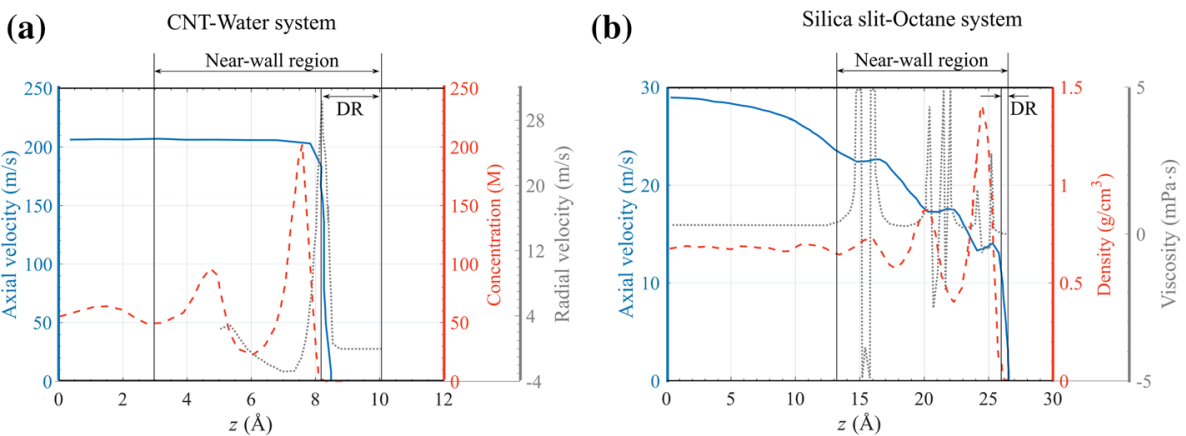

Fig. 2 MD data for a water transport in a 2.17-nm CNT (Joseph and Aluru 2008) and b octane transport in a 5.24-nm silica slit (Wang et al. 2016). The information in $\mathbf{b}$ is discussed in Sect. 3.1.1. "DR" denotes the depletion region

$$
f=\left(\frac{\mu_{\mathrm{b}}}{\mu_{\mathrm{w}}}-1\right)\left(1-\lambda_{\mathrm{b}}^{2}\right)+\lambda_{\mathrm{s}},
$$

where

$$
\lambda_{\mathrm{b}}=\left(1-\frac{\delta_{\mathrm{w}}}{r_{\mathrm{p}}}\right)^{2}
$$

is the pore-structure factor and

$$
\lambda_{\mathrm{s}}=\frac{8 \mu_{\mathrm{b}} D_{\mathrm{s}} L_{\mathrm{s}}}{r_{\mathrm{p}}^{2} W_{A}}+1
$$

is the slippage factor (Thomas and McGaughey 2008; Mattia and Calabrò 2012). $r_{\mathrm{p}}$ is the pore radius. $L_{\mathrm{s}}$ is the straight pore length. $W_{\mathrm{A}}$ is the work of adhesion which quantifies the energy of liquid adhesion per solid surface area.

The presented $\lambda_{\mathrm{s}}$ (Eq. 7) has readily accounted for the effect of pore size and other transport properties, such as viscosity and surface diffusion, yet the impact of pore throat tortuosity and surface roughness is not quantified. To include tortuosity, we substitute $L_{\mathrm{s}}$ with a tortuous pore length $L_{\mathrm{p}}$. The relation of $L_{\mathrm{s}}$ and $L_{\mathrm{p}}$ is evaluated by the (diffusive) tortuosity (Ghanbarian et al. 2013):

$$
\tau=\left(\frac{L_{\mathrm{p}}}{L_{\mathrm{s}}}\right)^{2} .
$$

By introducing a tortuosity fractal dimension $D_{\mathrm{T}}$, we describe pore throat as fractals and the $L_{\mathrm{p}}$ is estimated by Eq. (24). To include the roughness effect, we recall a fractal relative roughness $\varepsilon$ in Eq. (28). By recalling Eqs. (24) and (28), the formulation of apparent liquid slippage is derived:

$$
\lambda_{\mathrm{s}, \mathrm{app}}=\left[\frac{2^{-D_{\mathrm{T}}+4} \mu_{\mathrm{b}} D_{\mathrm{s}} L_{\mathrm{s}}^{D_{\mathrm{T}}}}{\left(\bar{r}_{\mathrm{p}}\right)^{D_{\mathrm{T}}+1} W_{\mathrm{A}}}+1\right](1-\varepsilon)^{4},
$$


for a pore of the average radius $\left(\bar{r}_{\mathrm{p}}\right)$ weighted averaged over the REV, where $\bar{r}_{\mathrm{p}}=\bar{d}_{\mathrm{p}} / 2=-\int_{d_{\mathrm{p}, \text { min }}}^{d_{\mathrm{p} \text { max }}} d_{\mathrm{p}} \mathbf{d} N_{\mathrm{p}}\left(d_{\mathrm{p}}\right) / 2 N_{t}=\left(d_{\mathrm{p}, \min }-\gamma^{D_{\mathrm{p}}} d_{\mathrm{p}, \max }\right) D_{\mathrm{p}} /\left(2 D_{\mathrm{p}}-2\right) . N_{\mathrm{t}}$ is the total number of pores in an REV, estimated by $\gamma^{-D_{\mathrm{p}}} ; \gamma=d_{\mathrm{p}, \min } / d_{\mathrm{p}, \max }$ is the pore-size heterogeneity coefficient; $D_{\mathrm{p}}$ is the pore size fractal dimension.

Equation (9) is an important modification to Eq. (7) because the former allows one to quantify liquid slippage through a realistic pore structure, which is typically non-straight and rough. When $D_{\mathrm{T}}=1$ and $\varepsilon=0$, Eq. (9) reduces to Eq. (7) for a straight and smooth pore.

\subsection{Apparent Liquid Permeability (ALP)}

The intrinsic permeability is derived by recalling Eq. (27) and the fractal relations of pore size (Eq. 25), pore throat tortuosity (Eq. 24), and pore-surface roughness distributions (Eq. 26) in an REV:

$$
k=\frac{d_{\mathrm{p}, \max }^{2}}{32} \frac{\phi}{\tau\left(d_{\mathrm{p}, \max }\right)} \xi\left(D_{\mathrm{T}}, D_{\mathrm{p}}, \varepsilon, \gamma\right),
$$

where

$$
\xi\left(D_{\mathrm{T}}, D_{\mathrm{p}}, \varepsilon, \gamma\right)=\frac{\left(-D_{\mathrm{T}}-D_{\mathrm{p}}+3\right)(1-\varepsilon)^{4}}{\left(D_{\mathrm{T}}-D_{\mathrm{p}}+3\right)\left(1-\gamma^{-D_{\mathrm{T}}-D_{\mathrm{p}}+3}\right)} .
$$

is the fractal function that embraces surface roughness and pore size distribution information. $d_{\mathrm{p}, \max }$ is the maximum pore diameter in the REV. $\phi=\gamma^{3-D_{\mathrm{p}}}$ is the fractal porosity (Wei et al. 2015; Boming 2008). $\tau\left(d_{\mathrm{p}, \max }\right)=\left(d_{\mathrm{p}, \max } / L_{\mathrm{s}}\right)^{-2 D_{\mathrm{T}}+2}$ is the tortuosity of the maximum pore diameter, derived by combining Eqs. (8) and (24). Relevant pore-scale fractal models are presented in "Appendix A".

Combining Eqs. (5) and (10) yields the ALP:

$$
\begin{aligned}
k_{\mathrm{app}}= & k \times f \\
= & \left\{\left(\frac{\mu_{\mathrm{b}}}{\mu_{\mathrm{w}}}-1\right)\left[1-\left(1-\frac{\delta_{\mathrm{w}}}{\bar{r}_{\mathrm{p}}}\right)^{4}\right]+\lambda_{\mathrm{s}}\right\} \\
& \times \frac{d_{\mathrm{p}, \text { max }}^{2 D_{\mathrm{T}}}}{32 L_{\mathrm{s}}^{2 D_{\mathrm{T}}-2}} \frac{\left(-D_{\mathrm{T}}-D_{\mathrm{p}}+3\right)}{\left(D_{\mathrm{T}}-D_{\mathrm{p}}+3\right)} \frac{\gamma^{-D_{\mathrm{p}}+3}}{\left(1-\gamma^{-D_{\mathrm{T}}-D_{\mathrm{p}}+3}\right)}(1-\varepsilon)^{4} \\
= & \left\{\left(\frac{\mu_{\mathrm{b}}}{\mu_{\mathrm{w}}}-1\right)\left[1-\left(1-\frac{\delta_{\mathrm{w}}}{\bar{r}_{\mathrm{p}}}\right)^{4}\right]+\left[\frac{2^{-D_{\mathrm{T}}+4} \mu_{\mathrm{b}} D_{\mathrm{s}} L_{\mathrm{s}}^{D_{\mathrm{T}}}}{\left(\bar{r}_{\mathrm{p}}\right)^{D_{\mathrm{T}}+1} W_{\mathrm{A}}}+1\right]\right\} \\
& \times \frac{d_{\mathrm{p}, \max }^{2 D_{\mathrm{T}}}}{32 L_{\mathrm{s}}^{2 D_{\mathrm{T}}-2}} \frac{\left(-D_{\mathrm{T}}-D_{\mathrm{p}}+3\right)}{\left(D_{\mathrm{T}}-D_{\mathrm{p}}+3\right)} \frac{\gamma^{-D_{\mathrm{p}}+3}}{\left(1-\gamma^{-D_{\mathrm{T}}-D_{\mathrm{p}}+3}\right)}(1-\varepsilon)^{4} .
\end{aligned}
$$

where $\lambda_{\mathrm{s}}$ is substituted with $\lambda_{\mathrm{s} \text {,app }} /(1-\varepsilon)^{4}$. The derived ALP model is then applied to estimate apparent permeability in inorganic matters $\left(k_{\mathrm{i}, \text { app }}\right)$ and organic matters $\left(k_{\mathrm{o} \text {,app }}\right)$. 


\subsection{ALP Estimation Workflow}

To demonstrate the use of the ALP model, we here provide a workflow to estimate ALP parameters using laboratory experimental and MD results. Table 2 summarizes the data

Table 2 Input data for the ALP model, aggregated from literature, and compiled

\begin{tabular}{|c|c|c|}
\hline Properties & Values (SI unit) & References \\
\hline \multicolumn{3}{|l|}{ Inorganic matrix } \\
\hline$d_{\mathrm{pi}, \max }$ & $1.63 \times 10^{-5} \mathrm{~m}$ & Josh et al. (2012) \\
\hline$d_{\mathrm{pi}, \min }$ & $2.30 \times 10^{-8} \mathrm{~m}$ & Josh et al. (2012) \\
\hline$\gamma_{\mathrm{i}}$ & $1.42 \times 10^{-3}$ & $\gamma_{\mathrm{i}}=d_{\mathrm{pi}, \min } / d_{\mathrm{pi}, \max }$ \\
\hline$\phi_{\mathrm{i}}$ & 0.06 & Fan and Ettehadtavakkol (2017a) \\
\hline$D_{\mathrm{pi}}$ & 2.57 & $D_{\mathrm{pi}}=3-\ln \left(\phi_{\mathrm{i}}\right) / \ln \left(\gamma_{\mathrm{i}}\right)$ \\
\hline$\tau_{\mathrm{i}}$ & 66 & $\tau_{\mathrm{i}}=\phi_{\mathrm{i}}^{-1.49}$ in Chen et al. (2015a) \\
\hline$D_{\mathrm{Ti}}$ & 1.38 & $D_{\mathrm{Ti}}=1-\ln \left(\tau_{\mathrm{i}}\right) / 2 \ln \left(\bar{d}_{\mathrm{pi}} / L_{\mathrm{si}}\right)$ \\
\hline$\beta_{\mathrm{i}}$ & 0.02 & Yang et al. (2014) \\
\hline$\alpha_{\mathrm{i}}$ & 0.002 & $\alpha_{\mathrm{i}}=\beta_{\mathrm{i}}^{3-D_{\mathrm{ci}}}$ \\
\hline$\left(h_{\mathrm{ci}, \max }\right)_{d_{\mathrm{p}, \mathrm{min}}} / d_{\mathrm{pi} \text {,min }}$ & 0.50 & SEM images in Yang et al. (2015a) \\
\hline$D_{\text {ci }}$ & 1.40 & Yang et al. (2015b) \\
\hline$L_{\mathrm{si}}=d_{\mathrm{mi}}$ & $1 \times 10^{-5} \mathrm{~m}$ & Chen et al. (2015b) \\
\hline$\mu_{\mathrm{b}}$ & $9.6 \times 10^{-4} \mathrm{~Pa} \cdot \mathrm{s}$ & Whitby et al. (2008) \\
\hline$\mu_{\mathrm{b}} / \mu_{\mathrm{w}}$ & 1.67 & Mattia and Calabrò (2012) \\
\hline$\delta_{\mathrm{w}}$ & $7 \times 10^{-10} \mathrm{~m}$ & $\begin{array}{l}\text { Joseph and Aluru (2008) and Mat- } \\
\text { tia and Calabrò (2012) }\end{array}$ \\
\hline$D_{\mathrm{si}}$ & $3 \times 10^{-9} \mathrm{~m}^{2} / \mathrm{s}$ & Mattia and Calabrò (2012) \\
\hline$W_{A i}$ & $0.025 \mathrm{~J} / \mathrm{m}^{2}$ & Hassenkam et al. (2009) \\
\hline \multicolumn{3}{|l|}{ Organic matrix } \\
\hline$d_{\mathrm{po}, \max }$ & $8.88 \times 10^{-8} \mathrm{~m}$ & Josh et al. (2012) \\
\hline$d_{\mathrm{po}, \min }$ & $3.84 \times 10^{-9} \mathrm{~m}$ & Josh et al. (2012) \\
\hline$\gamma_{\mathrm{o}}$ & $4.32 \times 10^{-2}$ & $\gamma_{\mathrm{o}}=d_{\mathrm{po}, \min } / d_{\mathrm{po}, \max }$ \\
\hline$\phi_{\mathrm{o}}$ & 0.03 & Fan and Ettehadtavakkol (2017a) \\
\hline$D_{\mathrm{po}}$ & 1.88 & $D_{\mathrm{po}}=3-\ln \left(\phi_{\mathrm{o}}\right) / \ln \left(\gamma_{\mathrm{o}}\right)$ \\
\hline$\tau_{\mathrm{o}}$ & 4518 & $\tau_{\mathrm{o}}=\phi_{\mathrm{o}}^{-2.40}$ in Chen et al. $(2015 \mathrm{c})$ \\
\hline$D_{T o}$ & 1.86 & $D_{T o}=1-\ln \left(\tau_{\mathrm{o}}\right) / 2 \ln \left(\bar{d}_{\mathrm{po}} / L_{\mathrm{so}}\right)$ \\
\hline$\beta_{\mathrm{o}}$ & 0.02 & Yang et al. (2014) \\
\hline$\alpha_{\mathrm{o}}$ & 0.001 & Javadpour et al. (2015) \\
\hline$\left(h_{\mathrm{co}, \max }\right)_{d_{\mathrm{p}, \min }} / d_{\mathrm{po}, \min }$ & 0.05 & $\begin{array}{l}\text { SEM images in Javadpour et al. } \\
\text { (2015) and Yang et al. (2015b) }\end{array}$ \\
\hline$D_{\text {co }}$ & 1.23 & $D_{\text {co }}=3-\ln \left(\alpha_{\mathrm{o}}\right) / \ln \left(\beta_{\mathrm{o}}\right)$ \\
\hline$L_{\mathrm{so}}=d_{m o}$ & $1 \times 10^{-6} \mathrm{~m}$ & Chen et al. (2015b) \\
\hline$\mu_{\mathrm{b}} / \mu_{\mathrm{w}}$ & 0.91 & Zhang et al. (2017) \\
\hline$\delta_{\mathrm{w}}$ & $1 \times 10^{-9} \mathrm{~m}$ & Wang et al. (2015) \\
\hline$D_{\text {so }}$ & $1 \times 10^{-9} \mathrm{~m}^{2} / \mathrm{s}$ & Ershov et al. (2001) \\
\hline$W_{\text {Ao }}$ & $0.144 \mathrm{~J} / \mathrm{m}^{2}$ & Mattia and Calabrò (2012) \\
\hline
\end{tabular}


for the key fractal and transport parameters reported in the literature. Figure 3 illustrates this workflow, summarized in three major steps:

Step 1 Quantify pore structure to calculate $k$ in Eq. (10).

Step 2 Quantify liquid transport, where we model the bulk flow region, the near-wall region, and strength of liquid-solid interactions to calculate $f$ in Eqs. (5) through (9).

Step 3 Couple Steps 1 and 2 to derive $k_{\text {app }}$ in Eq. (12).

Pore size distribution (PSD) Mercury injection capillary pressure (MICP) test is classically used to estimate PSDs (Josh et al. 2012). Figure 3a shows the MICP results of a bimodal PSD for a shale sample. Following the methodology by Naraghi and Javadpour (2015), the bimodal PSD is divided into two distributions: a widely spread inorganic distribution and a narrowly spread organic distribution. The distributions are parameterized by the pore size fractal relation in Eq. (25).

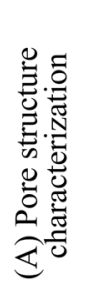

(a) MICP test

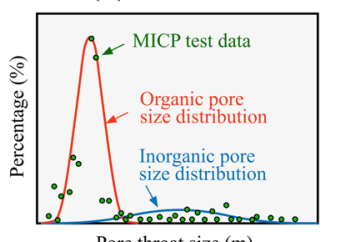

Pore throat size $(\mathrm{m})$

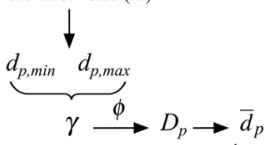

(b) LB simulations
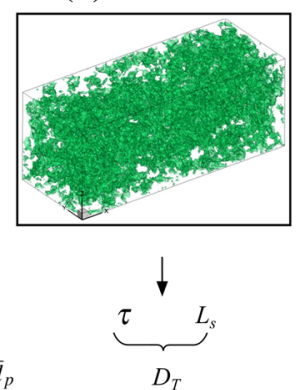

(c) SEM of shale samples

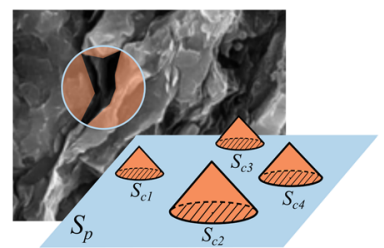

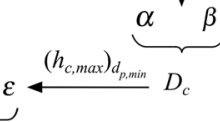
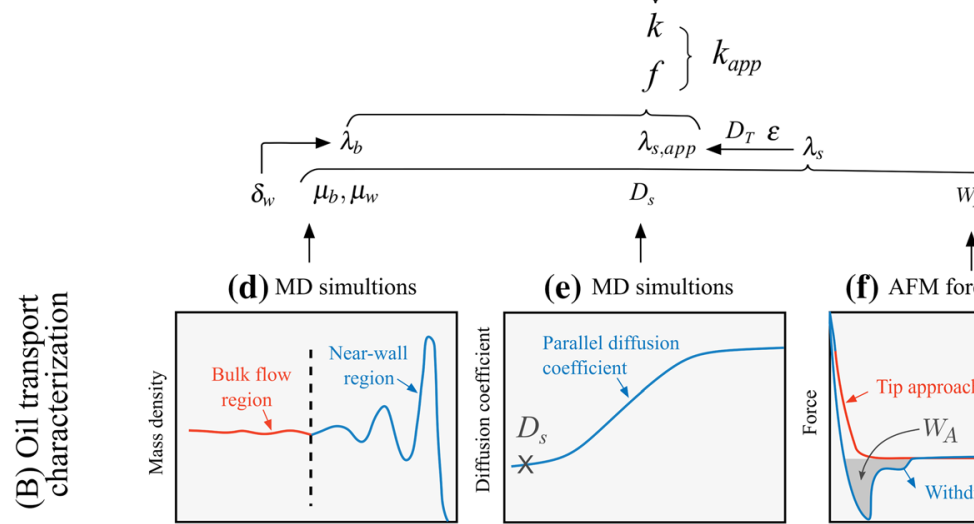

(d) MD simultions

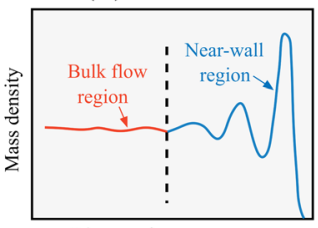

Distance from pore center

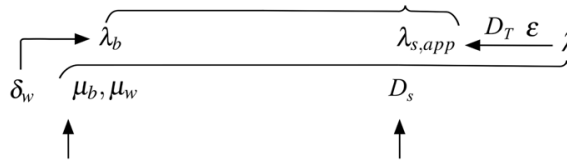

(e) MD simultions

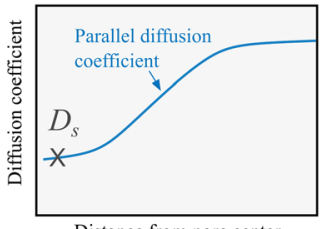

Distance from pore center

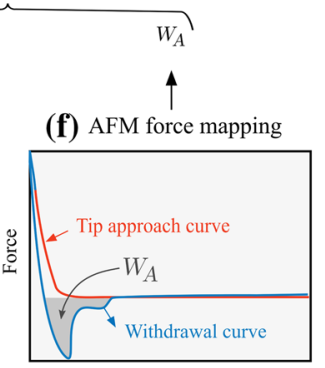

Tip distance

Fig. 3 Flowchart of the ALP model for nanoporous shales (Fan et al. 2018, 2019b). a-c Extraction of pore structure information, i.e., pore size, tortuosity, and surface roughness via of MICP experiments, LB simulations (Chen et al. 2015a), and SEM images (Yang et al. 2015a), respectively. d-f Quantification of oil transport properties, i.e., near-wall region thickness and viscosity, surface diffusion, and work of adhesion via MD simulations and AFM force mapping, respectively. Intrinsic permeability $(k)$ and flow enhancement factor $(f)$ are coupled to estimate $\operatorname{ALP}\left(k_{\text {app }}\right)$ 
Pore throat tortuosity Tortuosity data are usually acquired by flow simulations, e.g., lattice Boltzmann (LB) simulations (Fig. 3b). The (diffusive) tortuosity (Eq. 8) is found to obey an empirical, power-law scaling law with porosity, i.e., the Bruggeman's equation: $\tau=\phi^{-n}$ (Chen et al. 2015a; Shen and Chen 2007). This scaling law allows us to acquire the estimated $\tau$ from the flow simulation results. Once $\tau$ is obtained, we are able to parametrize pore throat fractals, e.g., $D_{\mathrm{T}}$. The exponent $n$ is empirical and varies with pore structures of different samples. For high-porosity media, $n$ was estimated $\sim 0.5$ (Shen and Chen 2007). For low-porosity shale samples, the LB simulations yielded $n=1.33-1.65$ for shale bulk (Chen et al. 2015a) and 1.8-3 for organic matters in shale (Chen et al. 2015c). We accordingly adopt the average $n$ to calculate tortuosity for inorganic pores $\left(\tau_{\mathrm{i}}\right)$ and organic pores $\left(\tau_{\mathrm{o}}\right): \tau_{\mathrm{i}}=\phi_{\mathrm{i}}^{-1.49}=66$ and $\tau_{\mathrm{o}}=\phi_{\mathrm{o}}^{-2.40}=4518$, where porosity $\phi_{\mathrm{i}}=0.06$ and $\phi_{\mathrm{o}}=0.03$, as summarized in Table 2. The estimated tortuosity values are in the typical range of shale samples reported from the literature, i.e., 100-1000 (Backeberg et al. 2017; Ghanbarian and Javadpour 2017; Woodruff et al. 2015).

Pore-surface roughness Equation (28) is used to estimate the relative roughness on pore surfaces. Figure $3 \mathrm{c}$ is an example SEM image of inorganic matters (Yang et al. 2015a) in a shale sample; it also illustrates the schematic of modeling surface roughness as many conical nanostructures inside the pore as well as shows the distribution of those nanostructures if the pore surface "spreads out" as a plane. Key parameters such as the areal ratio $(\alpha)$ and conical height $\left(\left(h_{\mathrm{c}}\right)_{d_{\mathrm{p}}}\right)$ in Eq. (28) are estimated via length and areal calculations of the structures observed in the SEM images. The fractal dimension of the conical base size distribution $\left(D_{\mathrm{c}}\right)$ is estimated via interpreting conical base size and number of cones and using Eq. (26).

Near-wall region Figure 3d shows the MD results of octane density in an inorganic pore (Wang et al. 2016). From the density fluctuation, we identify the near-wall region and the bulk flow region. Based on the MD results, the thickness fraction of the near-wall region $\left(\delta_{\mathrm{w}} / r_{\mathrm{pi}}\right)$ and the factor $\lambda_{b i}$ are estimated by Eq. (6). A similar procedure is conducted for estimating parameters of octane transport through an organic pore.

Surface diffusion, work of adhesion, slippage, and flow enhancement The surface diffusion coefficient $\left(D_{\mathrm{s}}\right)$ is derived from MD simulations by evaluating the self-diffusion coefficient parallel with the wall in which the coefficient in the first molecular layer is adopted as the value of $D_{\mathrm{s}}$, as shown in Fig. 3e. The work of adhesion is obtained via atomic force microscopy (AFM) mapping results. Figure $3 \mathrm{f}$ presents the AFM map of force versus distance for tip approach and withdrawal (Hassenkam et al. 2009; Argyris et al. 2011; Kobayashi et al. 2016), where the encompassed gray area estimates the work of adhesion $W_{A}$. The apparent slippage factor $\left(\lambda_{\mathrm{s}, \mathrm{app}}\right)$ is estimated by $\mu_{\mathrm{b}}, \mu_{\mathrm{w}}, D_{\mathrm{s}}, W_{\mathrm{A}}, D_{\mathrm{T}}$, and $\varepsilon$. The flow enhancement factor $(f)$ is calculated based on $\lambda_{\mathrm{s} \text {,app }}$ and $\lambda_{\mathrm{b}}$.

Literature data for confined oil transport We review some literature data of key transport properties of hydrocarbon liquids on hydrophilic and hydrophobic surfaces in Table 5. Through examining Table 5, we find: (1) A wide range of slip length of octane has been reported, i.e., 0 to $>130 \mathrm{~nm}$ in different MD studies, implying a strong dependence of liquid slippage on the substrate type, driving force, and substrate surface roughness. (2) The total near-wall region thickness $\left(2 \delta_{\mathrm{w}}\right)$ of octane is found dependent on the pore confinement: In narrow hydrophilic slits, e.g., $H=2 \mathrm{~nm}$, the fluctuation of near-wall viscosity may not stabilize at the slit center, which diminishes the bulk region and cause $2 \delta_{\mathrm{w}} / H \rightarrow 1$; In narrow hydrophobic slits, e.g., $H<3.9 \mathrm{~nm}$, the bulk-density may not present, which is due to the superimposition of the interaction potentials as well as the adsorption layers from substrate surfaces. Compared to the near-wall thickness in hydrophilic slits, total 
adsorption layer thickness fraction in hydrophobic slits is more consistent for 2-5-nm slits, i.e., around $40-50 \%$ of the entire flow region. (3) $W_{\mathrm{A}}$ and $D_{\mathrm{s}}$ data for octane are generally limited in the current body of the literature.

\section{Results}

\subsection{Validation Against MD Data}

Recent ALP models on liquid slippage in shale matrices have shown their ability to predict the enhancement of the confined water transport in straight nanotubes via MD data, yet their capability of predicting liquid (including oil and water) transport in tortuous and rough nanopores is unknown (Cui et al. 2017; Fan et al. 2019a; Zhang et al. 2017; Wang et al. 2019b). Here, we validate our model against a series of MD data in the literature for

1. confined octane transport in straight slit pores, estimated by Eq. (13);

2. confined liquid transport in tortuous cylindrical pores, estimated by Eq. (15);

3. confined liquid transport in rough cylindrical pores, estimated by Eq. (9).

\subsubsection{Confined Octane Transport in Straight Slit Pores}

In prior studies, the Ruckenstein's slip (Eq. 4b) was applied to confined water flow through CNTs (Mattia and Calabrò 2012). Recently proposed ALP models (Cui et al. 2017; Fan et al. 2019a; Zhang et al. 2017; Wang et al. 2019b) assumed that Eq. (4b) is capable of describing the slip length of oil flows; however, direct MD validations are lacking. Indeed, Eq. (4b) is the basis of Eq. (9), of which the latter is an important ingredient of the ALP model proposed in this work. We revisit Ruckenstein's slip model to investigate whether its theory can describe the oil slippage. For slit pore configurations, the Ruckenstein's slip model is corrected as Zhao et al. (2017):

$$
l_{\text {slip }}=\frac{2 \mu_{\mathrm{w}} L_{\mathrm{s}} D_{\mathrm{s}}}{H W_{\mathrm{A}}} .
$$

To validate Eq. (13) for shale oil transport, we compile the MD data in Table 3 for octane flow through a straight, silica slit (Wang et al. 2016). The velocity profile is presented in Fig. 2b. In Eq. (13), we assume that:

1. $L_{\mathrm{S}}$ is the length of the slit in the axial direction.

2. Slit confinement has little impact on the liquid adsorption, i.e., $W_{\mathrm{A}}$ is independent of $H$.

3. The values of $D_{\mathrm{s}}$ and $\mu_{\mathrm{w}}$ vary with $H$ [according to MD simulation results (Elwinger et al. 2017; Wang et al. 2018; Zhang et al. 2019)].

The following algorithm is implemented to estimate $l_{\text {slip }}$ for different slit apertures:

Step 1 Estimate $l_{\text {slip }}$ from the MD velocity profile for the 5.24-nm slit. The value of $l_{\text {slip }}$ is estimated by extrapolating the MD velocity beyond the liquid-solid interface until the liquid velocity vanishes, where $l_{\text {slip }}=-v_{\text {slip }} /(\mathbf{d} v / \mathbf{d} z)_{\text {wall }}, v_{\text {slip }}$ is the slip 
Table 3 MD data (Wang et al. 2016) for octane transport through a $5.24 \mathrm{~nm}$ silica slit

\begin{tabular}{lll}
\hline & Property & Value \\
\hline Input & Slit length $L_{\mathrm{s}}(\mathrm{nm})$ & 2.9 \\
& Slit aperture $H(\mathrm{~nm})$ & 5.24 \\
& Surface diffusion coefficient $D_{\mathrm{s}}\left(\mathrm{m}^{2} / \mathrm{s}\right)$ & $2.88 \times 10^{-9}$ \\
& Bulk viscosity $\mu_{\mathrm{b}}(\mathrm{mPa} \cdot \mathrm{s})$ & 0.359 \\
& Effective viscosity $\mu_{\text {eff }}(\mathrm{mPa} \cdot \mathrm{s})$ & 0.295 \\
Output & 0.874 \\
& Slip length $l_{\text {slip }}(\mathrm{nm})$ from Step 1 & 1.26 \\
& Near-wall thickness $\delta_{\mathrm{w}}(\mathrm{nm})$ from Step 2 & 0.226 \\
& Near-wall viscosity $\mu_{\mathrm{w}}(\mathrm{mPa} \cdot \mathrm{s})$ from Step 3 & $8.24 \times 10^{-4}$ \\
& Work of adhesion $W_{\mathrm{A}}\left(\mathrm{J} / \mathrm{m}^{2}\right)$ from Step 4 & \\
\hline
\end{tabular}

velocity at the wall, $z$ is the direction perpendicular to the wall (Lee and Choi 2008).

Step 2 Estimate $\delta_{\mathrm{w}}$ based on the MD density profile for the 5.24-nm slit (Fig. 2b).

Step 3 Estimate $\mu_{\mathrm{w}}$ for the 5.24-nm slit from the MD viscosity profile via either of the following methods. One can estimate $\mu_{\mathrm{w}}$ via averaging the liquid viscosity in the identified the near-wall region from Step 2. An alternative method is to calculate $\mu_{\mathrm{w}}$ from the effective viscosity data ( $\mu_{\mathrm{eff}}$ ) if the latter is available. The effective viscosity is the weighted average based on the fraction of the cross-sectional areas of the bulk flow and the near-wall region, i.e., Eq. (2b): $\mu_{\text {eff }}=\mu_{\mathrm{w}} A_{\mathrm{w}} / A_{\mathrm{t}}+\mu_{\mathrm{b}}\left(1-A_{\mathrm{w}} / A_{\mathrm{t}}\right)$ where $A_{\mathrm{w}}=2 \delta_{\mathrm{w}} L$ and $A_{\mathrm{t}}=H L$ are the crosssectional area of the near-wall region of thickness $\delta_{\mathrm{w}}$ and the entire flowing region in an $\mathrm{H}$-aperture slit, respectively. In this way,

$$
\mu_{\mathrm{w}}=\frac{H}{2 \delta_{\mathrm{w}}}\left[\mu_{\mathrm{eff}}-\mu_{\mathrm{b}}\left(1-\frac{2 \delta_{\mathrm{w}}}{H}\right)\right] .
$$

Step 4 Estimate $W_{\text {A }}$ by Eq. (13).

Step 5 Repeat Step 1 for slit aperture $H=1.74 \mathrm{~nm}, 3.46 \mathrm{~nm}, 7.61 \mathrm{~nm}$, and $11.17 \mathrm{~nm}$.

Step 6 Estimate $D_{\mathrm{s}}$ for different slit apertures. In the literature, the self-diffusion coefficient $\left(D_{\text {self }}\right)$ of water, $n$-octane, octanol, dimethyl sulfoxide as well as supercritical methane were found to increase with confinement when $H \lesssim 10 \mathrm{~nm}$, the relation of which can be described in a linear function (Elwinger et al. 2017; Wang et al. 2018; Zhang et al. 2019). For all cases studied in Step 5, slit apertures are $<12$ nm; we assume that the linearity holds for the surface diffusion coefficient $D_{\mathrm{s}}$. Given $W_{\mathrm{A}}, \delta_{\mathrm{w}}, l_{\text {slip }}$ in Table 3 , we estimate $D_{\mathrm{s}}(H=7.61 \mathrm{~nm})=4.24 \times 10^{-9} \mathrm{~m}^{2} / \mathrm{s}$. Now, with $D_{\mathrm{s}}(H=5.24 \mathrm{~nm})$, the linear function of $D_{\mathrm{s}}=0.57 \mathrm{H}-0.1$ is obtained, where $H$ is in nm and $D_{\mathrm{s}}$ is in $1 \times 10^{-9} \mathrm{~m}^{2} / \mathrm{s}$. A series of $D_{\mathrm{s}}$ for $H \leq 12 \mathrm{~nm}$ is estimated accordingly.

Step 7 Repeat Steps 2 and 3 to estimate $\delta_{\mathrm{w}}$ and $\mu_{\mathrm{w}}$ for different slit apertures based on their density profiles. Density data can be found in Wang et al. (2016).

Step 8 Calculate $l_{\text {slip }}$ for different slit apertures by Eq. (13).

In Fig. 4a, the estimated $l_{\text {slip }}$ from Step 8 is plotted against MD predictions from Step 1. Although slightly overestimating the slip length (possibly due to the simplified approximation of $D_{\mathrm{s}}$ values), Eq. (13) generally captures the octane slippage in silica slits of $H \leq$ 
(a)

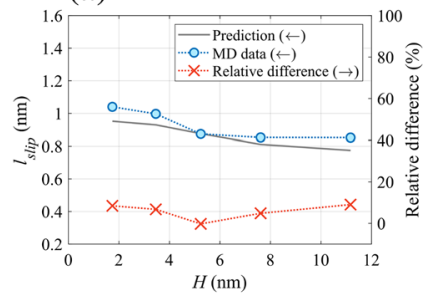

(b)

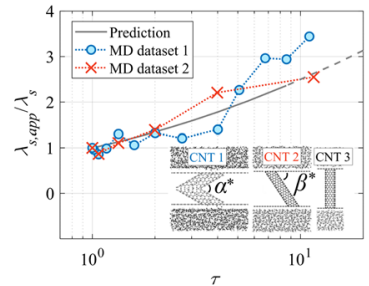

(c)

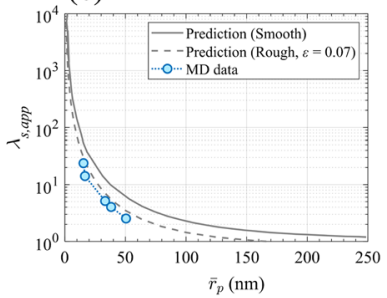

Fig. 4 a Comparison of the MD data (Wang et al. 2016) for octane transport in a silica slit versus predictions from Eq. (13). Relative differences are shown for prediction deviations from the MD data. b Comparison of the MD data for tortuous nanotubes versus $\lambda_{\text {s, app }}$ predictions from Eq. (15). MD dataset 1 (Qiu et al. 2015) and dataset 2 ( $\mathrm{Li}$ et al. 2015) correspond to CNT Type 1 with a bending angle $\alpha^{*}$ and Type 2 with a tilting angle $\beta^{*}$, respectively. Different tube tortuosities are achieved via alternating $\alpha^{*}$ and $\beta^{*}$; Tortuous length and tube size are fixed as $L_{\mathrm{p}}=3.8 \mathrm{~nm}$ and $d_{\mathrm{p}}=0.777 \mathrm{~nm}$ of CNT Type 1 ; and $L_{\mathrm{p}}=3.824 \mathrm{~nm}$ and $d_{\mathrm{p}}=0.782 \mathrm{~nm}$ of CNT Type 2. Straight CNT configuration is shown as CNT Type 3. Temperature $T=300$ $\mathrm{K}$; bulk viscosity $\mu_{\mathrm{b}} \approx 0.85 \mathrm{mPa}$ s (Kestin et al. 1984); work of adhesion $W_{\mathrm{A}}=97 \mathrm{~mJ} / \mathrm{m}^{2}$; surface diffusion coefficient $D_{\mathrm{s}}=4 \times 10^{-9} \mathrm{~m}^{2} / \mathrm{s}$ (Mattia and Calabrò 2012). c Comparison of the MD data for a rough nanotube (Secchi et al. 2016), a slip model for smooth CNTs (Zhang et al. 2017), versus $\lambda_{\mathrm{s} \text {,app }}$ predictions from Eq. (9)

$12 \mathrm{~nm}$, given the small difference, i.e., $\leq 9 \%$, observed between MD data and predictions. Direct MD data of $D_{\mathrm{s}}$ for different apertures can improve the $l_{\text {slip }}$ predictions when using Eq. (13).

\subsubsection{Confined Liquid Transport in Tortuous Cylindrical Pores}

We propose Eq. (9) to estimate apparent liquid slippage on tortuous, rough cylindrical nanopores. Assuming that the impact of surface roughness on liquid slippage is negligible (with $\varepsilon \rightarrow 0$ ) when compared to the impact of tortuosity, Eq. (9) reduces to

$$
\lambda_{\mathrm{s}, \mathrm{app}}=\frac{2^{-D_{\mathrm{T}}+4} \mu_{\mathrm{b}} D_{\mathrm{s}} L_{\mathrm{s}}^{D_{\mathrm{T}}}}{\left(\bar{r}_{\mathrm{p}}\right)^{D_{\mathrm{T}}+1} W_{\mathrm{A}}}+1
$$

To testify the ability of Eq. (15) to predict liquid slippage in tortuous pores, we adopt MD data for confined water transport in bent and tilted CNTs (Qiu et al. 2015; Li et al. 2015). For such geometry, Eq. (8) is further extended in terms of trigonometric ratios:

$$
\tau=\left(\frac{L_{\mathrm{p}}}{L_{\mathrm{s}}}\right)^{2}=\left[\sin \left(\frac{\alpha^{*}}{2}\right)\right]^{-2}=\left[\sin \left(\beta^{*}\right)\right]^{-2}
$$

where $\alpha^{*}$ and $\beta^{*}$ are bending and tilting angles, respectively, as illustrated in Fig. 4b.

To ensure that $D_{\mathrm{T}}$ is physically meaningful, i.e., $1 \leq D_{\mathrm{T}} \leq 3$, tortuosity should be $1 \leq\left[\tau=\left(d_{\mathrm{p}} / L_{\mathrm{s}}\right)^{-2 D_{\mathrm{T}}+2}\right] \leq\left(d_{\mathrm{p}} / L_{\mathrm{s}}\right)^{-4}$. The validity of Eq. (15), therefore, depends on the pore size distribution of the studied samples. For example, when $d_{\mathrm{p}} / L_{\mathrm{s}}>1$, Eq. (15) is not applicable; when $d_{\mathrm{p}} / L_{\mathrm{s}}=0.4$, Eq. (15) is applicable if tortuosity is $1 \leq \tau \leq 36$. Given the data for $d_{\mathrm{p}}$ and $L_{\mathrm{p}}$ (Qiu et al. 2015; Li et al. 2015) as well as the requirement of $1 \leq D_{\mathrm{T}} \leq 3$, Eq. (15) holds when the bending angle $\alpha^{*} \geq \frac{360}{\pi} \arcsin \left[\left(\frac{d_{\mathrm{p}}}{L_{\mathrm{p}}}\right)^{\frac{2}{3}}\right]=40.617^{\circ}$ and $\beta^{*} \geq \frac{180}{\pi} \arcsin \left[\left(\frac{d_{\mathrm{p}}}{L_{\mathrm{p}}}\right)^{\frac{2}{3}}\right]=20.309^{\circ}$. These angles correspond to $\tau \leq 8.3$.

The following algorithm is performed to validate Eq. (15): 
Step 1 Estimate $\tau$ via $\alpha^{*}$ or $\beta^{*}$ data and Eq. (16).

Step 2 Estimate $L_{\mathrm{s}}$ for different angles: $L_{\mathrm{s}}=L_{\mathrm{p}} \sin \left(\alpha^{*} / 2\right)=L_{\mathrm{p}} \sin \left(\beta^{*}\right)$.

Step 3 Estimate $D_{\mathrm{T}}$ via $\tau: D_{\mathrm{T}}=1-\frac{\ln (\tau)}{2 \ln \left(d_{\mathrm{p}} / L_{\mathrm{s}}\right)}$.

Step 4 Estimate $\lambda_{\mathrm{s}}$ for straight CNT (Type 3) by Eq. (7).

Step 5 Estimate $\lambda_{\text {s,app }}$ for tortuous CNTs (Types 1 and 2) by Eq. (15) with inputs of $D_{\mathrm{T}}$ from Step 3.

Figure $4 \mathrm{~b}$ compares the prediction results from Steps 4 and 5 against the MD data. Detailed descriptions of the dataset are captioned in Fig. 4b. The result demonstrates that Eq. (15) is a good predictor of the liquid slippage in tortuous pores.

\subsubsection{Confined Liquid Transport in Rough Cylindrical Pores}

Another feature of Eq. (9) is the consideration of surface roughness. In Eq. (9), roughness is modeled as resistance to liquid slippage. To validate this resistance effect, we adopt the MD data for confined water in straight, rough CNTs (Secchi et al. 2016). Figure 4c compares the MD data (Secchi et al. 2016), the apparent slippage factor estimated by Eq. (9) (with $D_{\mathrm{T}}=1$ for the straight CNT), and a slippage model for smooth CNTs (Zhang et al. 2017). The results show that the apparent slippage factor predicted by Eq. (9) agrees with the MD results better than the prior model for smooth CNTs (Zhang et al. 2017), which highlights the importance of the surface roughness on liquid slippage. Relative roughness is estimated to be $\varepsilon=0.07$ through data matching.

\subsection{Governing Factors of Confined Oil Transport}

This section presents the analysis results for the underlying factors that control oil transport in shale rocks.

Near-wall thickness Figure 5 shows the impact of the near-wall regions with respect to pore radii. We observe that a thicker near-wall region in inorganic pores improves the flow capability, while in organic pores it reduces the flow capability, although their influences are generally small. This observation is expected because the adhesive interactions between oil and inorganic surfaces are weaker than oil and organic surfaces.
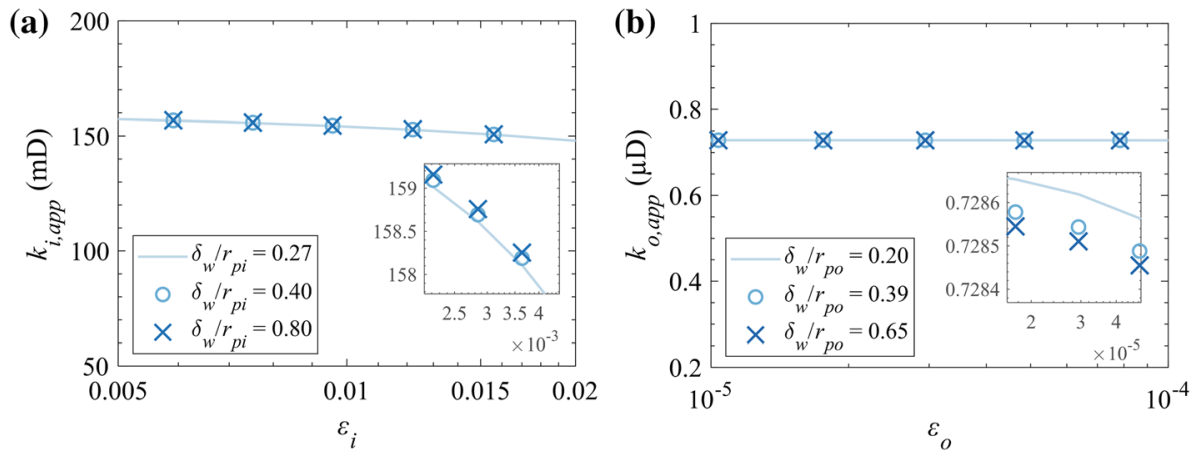

Fig. 5 Effect of near-wall thickness in $\mathbf{a}$ an inorganic pore and $\mathbf{b}$ an organic pore 
(a)

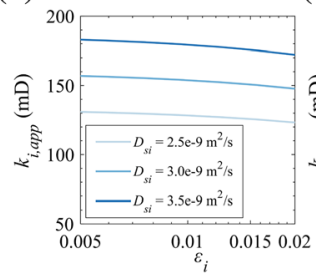

(b)

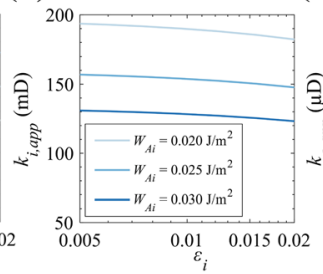

(c)

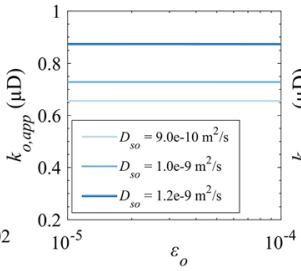

(d)

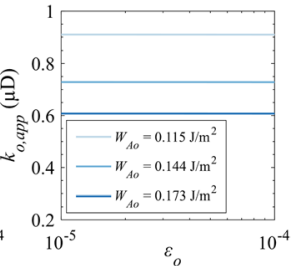

Fig. 6 Effect of surface diffusion $\left(D_{\mathrm{s}}\right)$ and work of adhesion $\left(W_{\mathrm{A}}\right)$ at increasing roughness $(\varepsilon)$. Subscripts $i$ and $o$ denote inorganic and organic pores, respectively
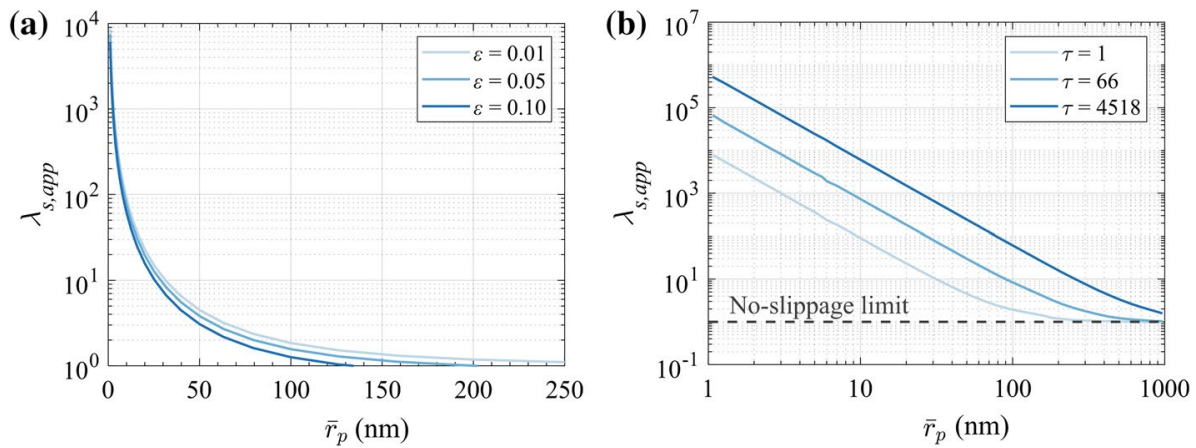

Fig. 7 Effect of pore size, tortuosity, and surface roughness on liquid slippage. The calculations are based on $d_{\mathrm{p}, \max }=10 \bar{r}_{\mathrm{p}}, \varepsilon=0$, and $\gamma=0.01$

Surface diffusion and work of adhesion Figure 6a, c presents the impact of $D_{\mathrm{s}}$ on the ALP in inorganic and organic pores, respectively. The ALP increases with the rise of $D_{\mathrm{s}}$. Oil slippage is more pronounced in inorganic pores (with a higher $D_{\mathrm{s}}$ and a lower $W_{\mathrm{A}}$ ) than in organic pores of the same diameter, which qualitatively agrees with MD observations of octane's transport through muscovite and kerogen pores (Ho and Wang 2019). Figure 6b, d shows the impact of $W_{\mathrm{A}}$ on the ALP for inorganic and organic pores, respectively. The ALP decreases with the increase of $W_{A}$ due to strong adhesion between liquid and pore surface and the resultant weaker slippage.

Pore confinement and surface roughness Figure $7 \mathrm{a}$ presents the impact of relative roughness on the apparent slippage factor $\left(\lambda_{\mathrm{s}, \mathrm{app}}\right)$. A higher relative roughness leads to a lower $\lambda_{\text {s,app }}$, which could quantitatively describe how liquid molecules tend to be "pinned to" the irregular wall surface (Granick et al. 2003). The sensitivity of ALP to surface roughness depends on pore type since organic pore surfaces are generally smoother and are more uniform than inorganic ones. The "resistance" effect of surface roughness is therefore not as evident in smoother organic pores as in rougher inorganic pores (See Fig. 6).

The impact of pore confinement on slippage is demonstrated in Fig. 7b. Slippage is strongly influenced by tortuosity. An increase in tortuosity of $4518 / 66 \approx 68$ or $66 / 1=66$ can enhance the slippage factor by 10 -folds for a pore radius of $1-100 \mathrm{~nm}$. Slippage is also 
influenced by pore size. Figure $7 \mathrm{~b}$ shows that the slippage factor decreases exponentially as the pore radius increases. When the pore radius reaches $100 \mathrm{~nm}$, slippage decreases until no flow enhancement is observed $\left(\lambda_{\mathrm{s}, \text { app }} \rightarrow 1\right)$.

Apparent versus intrinsic liquid permeability. Figure 8 shows the overall effect of pore confinement on the apparent and intrinsic liquid permeability, where important observations follow:

1. With a decrease in pore throat tortuosity and an increase in pore size, the intrinsic permeability increases.

2. When the pore size increases, the gap between apparent permeability ( $k_{\text {app }}$ in solid lines) and intrinsic permeability ( $k$ in dashed lines) becomes narrower and lines eventually overlap. This implies that the effect of pore size on flow enhancement fades as the pore size increases.

3. When the pore throat tortuosity is increased, the gap between apparent permeability and intrinsic permeability decreases for certain pore sizes, indicating a weakened slippage.

In Fig. 8a, with the increase of $\bar{r}_{\mathrm{p}}$, the points at which the lines of $k$ and $k_{\text {app }}$ start to overlap mark the onset of the diminished slippage: $\bar{r}_{\mathrm{p}} \gtrsim 100 \mathrm{~nm}$. This is also the condition of which pore radius exerts a pronounced positive effect on apparent permeability. We also find that pores with lower intrinsic permeability always have lower apparent permeability, which is because the strong effect of confinement on intrinsic permeability limits the effect of slippage on its apparent permeability even though considerable slippage occurs in highly confined pores. Comparative schematics of the impact of pore confinement on slippage and intrinsic permeability are illustrated in Fig. 8b.

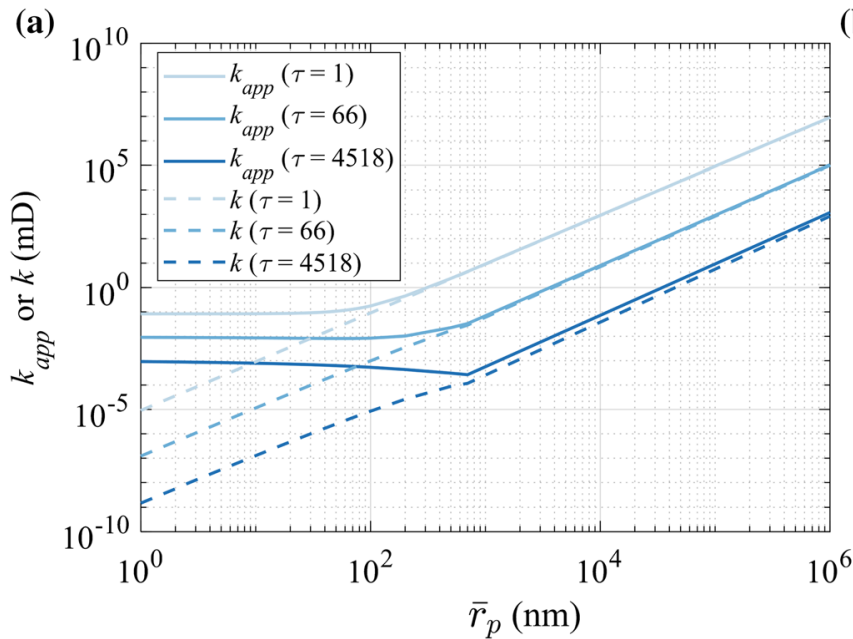

(b)

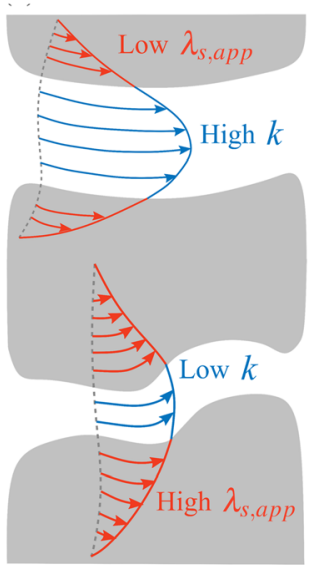

Fig. 8 a Apparent versus intrinsic liquid permeability under confinement. b Pore confinement exerts a negative effect on intrinsic permeability but a positive effect on liquid slippage. Presented are two representative pore-confinement conditions with two pore sizes and two pore throat tortuosities: a weakly confined pore (top) and a strongly confined pore (bottom) 


\section{Discussion}

\subsection{Liquid Transport Mechanisms in Shales}

Multiple structural and transport factors affect apparent liquid permeability and slippage as indicated by the ALP in Eq. (12). Dissimilarities in wettability, average pore size, and pore throat tortuosity for pores of different types in mixed-wet porous media further complicate slippage and permeation mechanisms. Table 4 summarizes the sensitivity comparisons conducted in this work.

Liquid viscosity near the pore wall can be different from the center of the pore due to the liquid-solid interactions. For example, if the work of adhesion is strong enough where the liquid tends to stick to pore surface, the near-wall viscosity is higher than the viscosity in the pore center. The sensitivity results indicate that viscosity variation near the pore wall may not have a significant impact on the flow enhancement unless the pore diameter is ultra-small, i.e., within an order of liquid molecule size. Given that in shale rocks, the largest connected pores have the most share of the contribution to the overall flow, one may conclude that the fluid viscosity change near the pore wall has a negligible effect compared to surface diffusion and wettability.

Pore size and its probability distribution as well as pore throat tortuosity are the most dominant structural factors of the ALP. Pore confinement has opposite effects on intrinsic permeability and liquid slippage as it restricts intrinsic permeability but enhances slippage. A quantitative comparison between the estimated range for the intrinsic and apparent permeability suggests that flow enhancement, mostly due to liquid slippage, can reach nearly 300 in both wetting and non-wetting pores. Here, the dual effect of liquid-solid interaction (wettability, adhesion, and surface diffusion) and pore confinement (pore size and pore throat tortuosity) renders such quantitatively comparable flow enhancement in inorganic and organic pores. Nonintuitively, such strong liquid slippage may not necessarily lead to a high apparent permeability when the intrinsic permeability is ultra-low, e.g., of organic matters.

Table 4 Summary of physics for oil slippage and apparent permeability in mixed-wet nanoporous shale

\begin{tabular}{|c|c|c|c|c|c|}
\hline Parameter & Physics & Inorganic pore & Organic pore & Comparison & \\
\hline \multirow{5}{*}{$\begin{array}{l}\text { Apparent } \\
\text { slip- } \\
\text { page } \\
\text { factor }\end{array}$} & \multirow{3}{*}{$\begin{array}{l}\text { Liquid- } \\
\text { solid } \\
\text { interac- } \\
\text { tion (LSI) }\end{array}$} & Hydrophilic & Hydrophobic & \multirow[t]{3}{*}{$\begin{array}{l}\text { Effect of LSIs cause: } \\
\lambda_{\text {si,app }}>\lambda_{\text {so,app }}\end{array}$} & \multirow{5}{*}{$\begin{array}{l}\text { Effect of LSIs and PC cause: } \\
\qquad \lambda_{\text {si,app }} \sim \lambda_{\text {so,app }}\end{array}$} \\
\hline & & Higher $D_{\text {si }}$ & Lower $D_{\text {so }}$ & & \\
\hline & & Lower $W_{A i}$ & Higher $W_{\text {Ao }}$ & & \\
\hline & \multirow{2}{*}{$\begin{array}{l}\text { Pore con- } \\
\text { finement } \\
\text { (PC) }\end{array}$} & Higher $\bar{r}_{\mathrm{pi}}$ & Lower $\bar{r}_{\text {po }}$ & \multirow[t]{2}{*}{$\begin{array}{c}\text { Effect of PC causes: } \\
\lambda_{\text {si,app }}<\lambda_{\text {so,app }}\end{array}$} & \\
\hline & & Lower $\tau_{\mathrm{i}}$ & Higher $\tau_{\mathrm{o}}$ & & \\
\hline \multirow{2}{*}{$\begin{array}{l}\text { Intrinsic } \\
\text { perme- } \\
\text { ability }\end{array}$} & \multirow{2}{*}{$\begin{array}{l}\text { Pore con- } \\
\text { finement } \\
\text { (PC) }\end{array}$} & Higher $\bar{r}_{\mathrm{pi}}$ & Lower $\bar{r}_{\text {po }}$ & \multirow[t]{2}{*}{$\begin{array}{l}\text { Effect of PC causes: } \\
k_{i} \gg k_{o}\end{array}$} & \\
\hline & & Lower $\tau_{\mathrm{i}}$ & Higher $\tau_{\mathrm{o}}$ & & \\
\hline $\begin{array}{l}\text { Apparent } \\
\text { perme- } \\
\text { ability }\end{array}$ & \multicolumn{3}{|c|}{ Oil slippage, adsorption, and intrinsic permeability } & \multicolumn{2}{|c|}{$\begin{array}{l}\text { Effect of LSIs and PC cause: } \\
\text { PC cause: } k_{i, a p p} \gg k_{o, a p p}\end{array}$} \\
\hline
\end{tabular}




\subsection{The ALP Model Comparison with the Carman and the Carman-Kozeny Equation}

It is instructive to understand the relation between the ALP and the fluid equations that predict the pressure drop of fluids through permeable media. We investigate two classic equations, namely Carman (1956) and Carman-Kozeny (Amaefule et al. 1993; Carman 1937) and show that under reasonable assumptions, the ALP will reduce to the spirit of these two classic equations.

To derive the Carman equation, we begin with a simple version of the ALP. Apply the assumptions of the Carman equation to Eq. (12), i.e., a constant viscosity distribution $\left(\mu_{\mathrm{b}}=\mu_{\mathrm{w}}\right)$, no surface diffusion $\left(D_{\mathrm{s}}=0\right)$, smooth surfaces $(\varepsilon=0)$, and uniform pore diameter $\left(d_{\mathrm{p}} \equiv d_{\mathrm{p}, \max }\right)$ and set the fractal parameters to $D_{\mathrm{T}}=1$ and $D_{\mathrm{p}}=2$, the ALP reduces to the Carman equation (Eq. 23) in the limit.

The Carman-Kozeny equation is used for predicting a fluid flowing through permeable media packed with spherical, smooth, and solid grains. A generalized version of the Carman-Kozeny equation is (Amaefule et al. 1993)

$$
k_{\mathrm{CK}}=\frac{1}{F_{\mathrm{s}} \tau S_{g v}^{2}} \frac{\phi^{3}}{(1-\phi)^{2}}=\frac{d_{\mathrm{p}}^{2}}{16 F_{\mathrm{s}}} \frac{\phi}{\tau},
$$

where $k_{\mathrm{CK}}$ is the Carman-Kozeny permeability, $F_{\mathrm{s}}$ is the pore shape factor, $S_{\mathrm{gv}}$ is the ratio of grain surface area to the grain volume $\left(S_{\mathrm{gv}}=4 \phi / d_{\mathrm{p}}(1-\phi)\right.$ for spherical grains). Equation (17) accounts for the porosity and geometric properties of grain and pore. The product of $F_{\mathrm{s}} \tau$ is referred to as the Kozeny constant and is a strong function of grain size distribution. The Kozeny constant is often fitted to the experimental data to obtain the best predictor of permeability based on the porosity for different hydraulic units. Equation (10) has the spirit of the Carman-Kozeny equation in Eq. (17) where the fractal function $(\xi)$ is the inverse of half the pore shape factor, i.e., $\xi=2 / F_{\mathrm{s}}$. For a bundle of identical straight cylinders, i.e., $F_{\mathrm{s}}=2$ and correspondingly $\xi=1$, Eq. (10) becomes identical to Eq. (17).

\subsection{The ALP Versus Klinkenberg Equation}

A fundamental insight into the fluid flow in ultra-confined media such as shale rocks is the presence of fluid slippage, regardless of the phase type. Gas slippage, also known as the Klinkenberg effect, occurs due to the rarefaction. Gas rarefaction is caused by a decrease in gas pressure, reduction in characteristic length, or pore size. Either of these factors increases the dimensionless Knudsen number $(K n)$, defined as a ratio of the mean free path $(\lambda)$ of the gas to the average pore diameter $\left(\bar{d}_{\mathrm{p}}\right)$. With the increase of $K n$, the gas flow becomes more rarefied and transitions from slip flow to transitional flow, and eventually to the free molecular flow (Darabi et al. 2012; Fan et al. 2020; Javadpour and Ettehadtavakkol 2015; Fan and Ettehadtavakkol 2017b).

For liquid flows, $\lambda$ is much smaller than $d_{\mathrm{p}}, K n$, therefore, cannot be a proper indicator of liquid slippage. Instead, $W_{\mathrm{A}}$ for liquid has a similar role as $K n$ for gas. $W_{\mathrm{A}}$ quantifies the energy required to overcome free energies per area of three-phase interfaces of liquid-solid, solid-vapor, and liquid-vapor and subsequently separate liquid phase from the solid phase, $W_{\mathrm{A}} \approx \gamma_{\mathrm{LV}}\left(1+\cos \theta\right.$ ) (Zisman 1964), where $\gamma_{\mathrm{LV}}$ is surface tension between the liquid and the saturated vapor in the unit of $N / m$, and $\theta$ is the contact angle between liquid-vapor and liquid-solid interfaces. $\gamma_{\mathrm{LV}}$ is related to $\mu_{\mathrm{w}}, \theta$ (also wettability), and $D_{\mathrm{s}}$. For 
example, a large $W_{\mathrm{A}}$ required to separate the liquid from the local site manifests in a small $\theta$, suggesting the liquid is less willing to flow near the surface, and slippage is small. The liquid slippage phenomenon is a synergic effect of all the above parameters.

Based on the sensitivity results, we find that the effect of $\mu_{\mathrm{w}}$ is much smaller than that $D_{\mathrm{s}}$ and $W_{\mathrm{A}}$. We, therefore, drop the flow contribution from the viscosity. Similarly, $\varepsilon$ can also be dropped as pore-surface roughness is less dominant than the $d_{\mathrm{p}}$ and $\tau$. Given that the fractal intrinsic permeability can essentially represent the Carman-Kozeny equation, the derived ALP in Eq. (12) can be arranged in terms of $k_{\mathrm{CK}}$ and $\tau$ as

$$
k_{\mathrm{CK}, \mathrm{app}}=k_{\mathrm{CK}}\left(1+\frac{b}{W_{A}}\right),
$$

where

$$
b=\frac{32 \mu_{\mathrm{b}} L_{\mathrm{s}} \tau^{\frac{1}{2}}}{\bar{d}_{\mathrm{p}}^{2}} D_{\mathrm{s}} .
$$

The simplified ALP model (Eq. 18) for liquid presents some interesting analogies as the Klinkenberg equation for gas (Klinkenberg et al. 1941). First, the liquid slippage is inversely proportional to $W_{\mathrm{A}}$, whereas the gas slippage is inversely proportional to the gas pressure. Second, the term $b$, defined here as the liquid slippage constant, determines the flow enhancement contribution upon the intrinsic $k_{\mathrm{CK}}$. It is a function of pore confinement, i.e., $\bar{d}_{\mathrm{p}}$ and $\tau$, and liquid $D_{\mathrm{s}}$. Interestingly, the term $b$ is similar to the gas slippage constant $\left(b^{\prime}\right)$ in the Klinkenberg equation as $b^{\prime}$ is found to be a strong function of $\tau$ and the gas-solid interaction parameter-the tangential momentum accommodation coefficient (TMAC) (Wu et al. 2017), where the TMAC characterizes the how gas molecules are reflected in terms of diffuse reflection and specular reflection on the wall after the gas-wall collision (Arkilic et al. 2001).

In a more general manner, by assuming that liquid would follow the hydraulic pathways of the pores, we define a dimensionless parameter, the liquid confinement number $(\mathrm{Cn})$, as the ratio of the tortuous path length to the characteristic length, to characterize the liquid slippage. In practice, the average pore diameter is applied as the characteristic length, therefore $C n=L_{\mathrm{s}} \sqrt{\tau} / \bar{d}_{\mathrm{p}}$. Equation (18) then reads

$$
k_{\mathrm{CK}, \text { app }}=k_{\mathrm{CK}}\left(1+\alpha^{\prime} \cdot \mathrm{Cn}\right)
$$

where the dimensionless parameter

$$
\alpha^{\prime}=\frac{32 \mu_{\mathrm{b}} D_{\mathrm{s}}}{\bar{d}_{\mathrm{p}} W_{A}}
$$

quantifies the surface diffusion of liquid of viscosity $\mu_{\mathrm{b}}$ in the straight pore of the diameter $\bar{d}_{\mathrm{p}}$ by overcoming the work of adhesion $W_{\mathrm{A}}$. Equation (20) shares a similar structure as the gas slippage model due to gas rarefaction (Beskok and Karniadakis 1999).

The derived ALP model in Eq. (12) along with its transformation in Eqs. (18) and (20) delivers a more comprehensive description of the liquid flow in tortuous, heterogeneous porous media, and under proper restricting assumptions, reduces to the spirit of the Carman-Kozeny equation. 


\section{Conclusions}

Liquid transport in shale rocks is governed by local pore confinement, liquid-solid interaction, and pore-surface roughness. We proposed an apparent liquid permeability (ALP) model for heterogeneous and rough nanoporous shale matrices, and a workflow for the ALP estimation. Major conclusions follow:

1. Inorganic pores and organic pores require separate modeling as they possess different pore size distribution, pore throat tortuosity, pore-surface roughness, pore surface wettability, and liquid-solid interaction.

2. Liquid slippage on a wetting surface is enhanced for a high pore-confinement effect, e.g., the strength of oil slippage in organic pores is quantitatively considerable to that in inorganic pores, due to high pore confinements.

3. Apparent permeability is restricted by high pore confinements.

4. Oil slippage abates when pore-surface roughness intensifies.

5. The ALP model shares some analogies with the Klinkenberg gas permeability and also converges to the Carman-Kozeny permeability when no-slip liquid flows through a bundle of homogeneous capillaries.

Open Access This article is licensed under a Creative Commons Attribution 4.0 International License, which permits use, sharing, adaptation, distribution and reproduction in any medium or format, as long as you give appropriate credit to the original author(s) and the source, provide a link to the Creative Commons licence, and indicate if changes were made. The images or other third party material in this article are included in the article's Creative Commons licence, unless indicated otherwise in a credit line to the material. If material is not included in the article's Creative Commons licence and your intended use is not permitted by statutory regulation or exceeds the permitted use, you will need to obtain permission directly from the copyright holder. To view a copy of this licence, visit http://creativecommons.org/licenses/by/4.0/.

\section{Appendix A: Review of Pore-Scale Fractal Models and the Intrinsic Permeability Model}

In an REV, pore space is conventionally modeled as a bundle of cylindrical tubes with a constant diameter $\left(d_{\mathrm{p}}\right)$ and a length $\left(L_{\mathrm{p}}\right)$. For a laminar viscous flow through an REV, a noslip boundary condition applies to solve the flow rate as

$$
Q=\frac{\pi d_{\mathrm{p}}^{4} \Delta P}{128 \mu_{\mathrm{b}} L_{\mathrm{p}}},
$$

where $Q$ is the intrinsic volumetric flow rate; $d_{\mathrm{p}}$ is pore diameter; $L_{\mathrm{p}}$ is tortuous pore length; $\Delta P$ is pressure difference; $\mu_{\mathrm{b}}$ is fluid viscosity. By applying Darcy's law to Eq. (22), permeability is solved as Carman's permeability (Carman 1956):

$$
k=\frac{\pi d_{\mathrm{p}}^{4}}{128 A},
$$

where $A$ is the cross-sectional area of the REV. 
The fractal theory is applied to model REV heterogeneities in pore throat tortuosity, pore size distribution, and roughness of pore surface (Yang et al. 2015b; Boming and Cheng 2002). First, pore throat tortuosity is modeled by a tortuosity fractal dimension $\left(D_{\mathrm{T}}\right)$ that relates the straight pore length $\left(L_{\mathrm{s}}\right)$ to tortuous pore length $\left(L_{\mathrm{p}}\right)$ as shown in Eq. (24). Second, the cumulative number of pores with a diameter greater than $d_{\mathrm{p}}$ is modeled as a function of the ratio of the maximum pore diameter $\left(d_{\mathrm{p} \text {, max }}\right)$ to the variable $d_{\mathrm{p}}$ in the REV, to the power of the pore size fractal dimension $\left(D_{\mathrm{p}}\right)$, as shown in Eq. (25). Third, we model pore-surface roughness as numerous conical nanostructures protruding from the inner surface of spherical pores, in which the cumulative number $\left(N_{\mathrm{c}}\right)$ of such nanostructures is a function of the ratio of the maximum conical base diameter $\left(d_{\mathrm{c}, \max }\right)$ to the variable $\left(d_{\mathrm{c}}\right)$ in the local pore, to the power of the fractal dimension of the conical base size distribution $\left(D_{c}\right)$, shown in Eq. (26).

$$
\begin{gathered}
L_{\mathrm{p}}\left(d_{\mathrm{p}}\right)=d_{\mathrm{p}}^{-D_{\mathrm{T}}+1} L_{\mathrm{s}}^{D_{\mathrm{T}}} \\
N_{\mathrm{p}}\left(d \geq d_{\mathrm{p}}\right)=\left(\frac{d_{\mathrm{p}, \max }}{d_{\mathrm{p}}}\right)^{D_{\mathrm{p}}} \\
N_{\mathrm{c}}\left(d \geq d_{\mathrm{c}}\right)=\left(\frac{d_{\mathrm{c}, \max }}{d_{\mathrm{c}}}\right)^{D_{\mathrm{c}}}
\end{gathered}
$$

By combining Eqs. (23) through (26), intrinsic permeability is derived as Yang et al. (2015b):

$$
k=\frac{\pi d_{\mathrm{p}, \max }^{D_{\mathrm{T}}+3} D_{\mathrm{p}} L_{\mathrm{s}}^{-D_{\mathrm{T}}+1}(1-\varepsilon)^{4}}{128 A\left(D_{\mathrm{T}}-D_{\mathrm{p}}+3\right)},
$$

where $\varepsilon$ is the relative roughness, defined as the ratio of double of the average height of conical nanostructures in a pore to its pore diameter $d_{\mathrm{p}}$, i.e., $\varepsilon=2\left(\bar{h}_{\mathrm{c}}\right)_{d_{\mathrm{p}}} / d_{\mathrm{p}}$. By solving for $\left(\bar{h}_{\mathrm{c}}\right)_{d_{\mathrm{p}}}, \varepsilon$ is derived as Eq. (28). Derivation of $\varepsilon$ is referred to Yang et al. $(2014,2015 \mathrm{~b})$.

$$
\varepsilon=\frac{2 \alpha}{3} \frac{\left(h_{\mathrm{c}, \max }\right)_{d_{\mathrm{p}, \text { min }}}}{d_{\mathrm{p}, \text { min }}} \frac{2-D_{\mathrm{c}}}{3-D_{\mathrm{c}}} \frac{1-\beta^{-D_{\mathrm{c}}+3}}{1-\beta^{-D_{\mathrm{c}}+2}},
$$

where $\left(h_{\mathrm{c}, \max }\right)_{d_{\mathrm{p}, \min }}$ is the maximum height of the cone in the minimum pore diameter $\left(d_{\mathrm{p}, \min }\right) ; \alpha$ is the ratio of the total cone base area $\left(S_{\mathrm{c} 1}+S_{\mathrm{c} 2}+S_{\mathrm{c} 3}+S_{\mathrm{c} 4}+\cdots\right)$ to the total pore surface area $\left(S_{\mathrm{p}}\right)$ (including protruding cone base area and non-protruding smooth area) in Fig. 3c; and $\beta$ is the ratio of the minimum to the maximum base diameter, given by $\beta=d_{\mathrm{c}, \min } / d_{\mathrm{c}, \max }$. With $D_{\mathrm{c}}$ approaching 0 , fewer conical nanostructures occupy pore surface; therefore, pore-surface roughness decreases.

In Eq. (27), the cross-sectional area of an REV $(A)$ cannot be measured directly: a common approach is to substitute $A$ with porosity $\phi$ as follows. Considering $N_{\mathrm{p}}$ numbers of tortuous cylinders for $3 \mathrm{D}$ pores in an REV, we calculate porosity by the volumetric ratio of pore space over the REV: 


$$
\begin{aligned}
\phi & =\frac{-\int_{d_{\mathrm{p}, \text { min }}}^{d_{\mathrm{p} \text { max }}}\left[\pi d_{\mathrm{p}}^{2} L_{\mathrm{p}}\left(d_{\mathrm{p}}\right)\right] \mathbf{d} N_{\mathrm{p}}\left(d_{\mathrm{p}}\right)}{4 A L_{\mathrm{s}}} \\
& =\frac{\pi d_{\mathrm{p}, \max }^{-D_{\mathrm{T}}+3} D_{\mathrm{p}} L_{\mathrm{s}}^{D_{\mathrm{T}}-1}\left(1-\gamma^{-D_{\mathrm{T}}-D_{\mathrm{p}}+3}\right)}{4 A\left(-D_{\mathrm{T}}-D_{\mathrm{p}}+3\right)}
\end{aligned}
$$

where $\gamma$ is the pore-size heterogeneity coefficient, defined as the ratio of the minimum to the maximum pore diameter in an REV, i.e., $\gamma=d_{\mathrm{p}, \min } / d_{\mathrm{p}, \max }$. By Eq. (29), $A$ is derived:

$$
A=\frac{\pi d_{\mathrm{p}, \max }^{-D_{\mathrm{T}}+3} D_{\mathrm{p}} L_{\mathrm{s}}^{D_{\mathrm{T}}-1}\left(1-\gamma^{-D_{\mathrm{T}}-D_{\mathrm{p}}+3}\right)}{4 \phi\left(-D_{\mathrm{T}}-D_{\mathrm{p}}+3\right)} .
$$

Substituting $A$ in Eq. (27) with (30), one can derive the intrinsic permeability as in Eq. (10).

\section{Appendix B: Derivation of Flow Enhancement}

The apparent volumetric flow rate in a pore is solved as Zhang et al. (2017)

$$
\begin{aligned}
Q_{\mathrm{app}}= & \frac{\pi \Delta P}{8 L_{\mathrm{p}}}\left\{\frac{\left(r_{\mathrm{p}}-\delta_{\mathrm{w}}\right)^{2}}{\mu_{\mathrm{b}}}\left[\frac{\mu_{\mathrm{b}}}{\mu_{\mathrm{w}}}\left(4 r_{\mathrm{p}} \delta_{\mathrm{w}}-2 \delta_{\mathrm{w}}^{2}\right)+\left(r_{\mathrm{p}}-\delta_{\mathrm{w}}\right)^{2}+\frac{8 \mu_{\mathrm{b}} D_{\mathrm{s}} L_{\mathrm{p}}}{W_{\mathrm{A}}}\right]\right. \\
& \left.+\frac{1}{\mu_{\mathrm{w}}}\left(2 r_{\mathrm{p}} \delta_{\mathrm{w}}-\delta_{\mathrm{w}}^{2}\right)\left(2 r_{\mathrm{p}} \delta_{\mathrm{w}}-\delta_{\mathrm{w}}^{2}+\frac{8 \mu_{\mathrm{w}} D_{\mathrm{s}} L_{\mathrm{p}}}{W_{\mathrm{A}}}\right)\right\},
\end{aligned}
$$

where $D_{\mathrm{s}}$ is the surface diffusion coefficient. A high value of $D_{\mathrm{s}}$ reflects a fast diffusion of liquid molecules on the surface. Measured $D_{\mathrm{s}}$ values for oil on different wettability surfaces are reported in the order of $1 \times 10^{-9} \mathrm{~m}^{2} / \mathrm{s}$ to $1 \times 10^{-8} \mathrm{~m}^{2} / \mathrm{s}$ (Mattia and Calabrò 2012; Ershov et al. 2001).

\section{Appendix C}

See Table 5. 


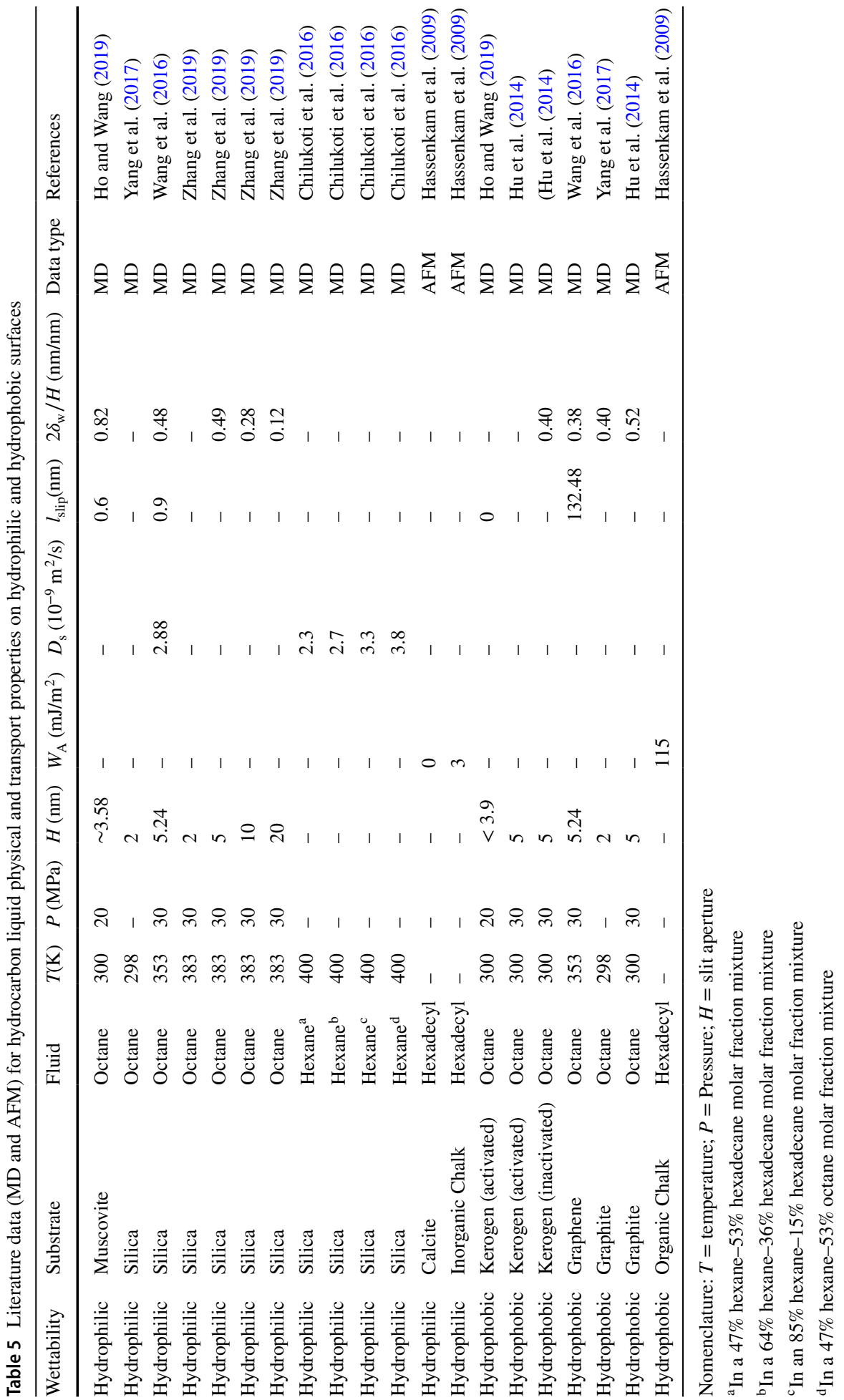




\section{References}

Amaefule, J.O., Altunbay, M., Tiab, D., Kersey, D.G., Keelan, D.K., et al.: Enhanced reservoir description: using core and log data to identify hydraulic (flow) units and predict permeability in uncored intervals/ wells. In: SPE Annual Technical Conference and Exhibition, Society of Petroleum Engineers (1993)

Ambrose, R.J., Hartman, R.C., Campos, M.D., Akkutlu, I.Y., Sondergeld, C.: New pore-scale considerations for shale gas in place calculations. In: SPE Unconventional Gas Conference, Society of Petroleum Engineers (2010)

Argyris, D., Ashby, P.D., Striolo, A.: Structure and orientation of interfacial water determine atomic force microscopy results: insights from molecular dynamics simulations. ACS Nano 5(3), 2215-2223 (2011)

Arkilic, E.B., Breuer, K.S., Schmidt, M.A.: Mass flow and tangential momentum accommodation in silicon micromachined channels. J. Fluid Mech. 437, 29-43 (2001)

Backeberg, N.R., Iacoviello, F., Rittner, M., Mitchell, T.M., Jones, A.P., Day, R., Wheeler, J., Shearing, P.R., Vermeesch, P., Striolo, A.: Quantifying the anisotropy and tortuosity of permeable pathways in clayrich mudstones using models based on X-ray tomography. Sci. Rep. 7(1), 1-12 (2017)

Beskok, A., Karniadakis, G.E.: Report: a model for flows in channels, pipes, and ducts at micro and nano scales. Microscale Thermophys. Eng. 3(1), 43-77 (1999)

Blake, T.D.: Slip between a liquid and a solid: DM Tolstoi's (1952) theory reconsidered. Colloids Surf. 47, 135-145 (1990)

Boming, Y.: Analysis of flow in fractal porous media. Appl. Mech. Rev. 61(5), 050801 (2008)

Boming, Y., Cheng, P.: A fractal permeability model for bi-dispersed porous media. Int. J. Heat Mass Transf. 45(14), 2983-2993 (2002)

Cao, B.-Y., Chen, M., Guo, Z.-Y.: Liquid flow in surface-nanostructured channels studied by molecular dynamics simulation. Phys. Rev. E 74(6), 066311 (2006)

Carman, P.C.: Fluid flow through granular beds. Trans. Inst. Chem. Eng. 15, 150-166 (1937)

Carman, P.C.: Flow of Gases Through Porous Media. Butterworths Scientific Publications, London (1956)

Chalmers, G.R., Bustin, R.M., Power, I.M.: Characterization of gas shale pore systems by porosimetry, pycnometry, surface area, and field emission scanning electron microscopy/transmission electron microscopy image analyses: examples from the Barnett, Woodford, Haynesville, Marcellus, and Doig units. AAPG Bull. 96(6), 1099-1119 (2012)

Chen, L., Zhang, L., Kang, Q., Viswanathan, H.S., Yao, J., Tao, W.: Nanoscale simulation of shale transport properties using the lattice Boltzmann method: permeability and diffusivity. Sci. Rep. 5, 8089 (2015a)

Chen, L., Kang, Q., Dai, Z., Viswanathan, H.S., Tao, W.: Permeability prediction of shale matrix reconstructed using the elementary building block mode. Fuel 160, 346-356 (2015b)

Chen, L., Kang, Q., Pawar, R., He, Y.-L., Tao, W.-Q.: Pore-scale prediction of transport properties in reconstructed nanostructures of organic matter in shales. Fuel 158, 650-658 (2015c)

Chilukoti, H.K., Kikugawa, G., Ohara, T.: Mass transport and structure of liquid $n$-alkane mixtures in the vicinity of alpha-quartz substrates. RSC Adv. 6(102), 99704-99713 (2016)

Christensen, M., Tanino, Y.: Enhanced permeability due to apparent oil/brine slippage in limestone and its dependence on wettability. Geophys. Res. Lett. 44(12), 6116-6123 (2017)

Cui, J.: Oil transport in shale nanopores and micro-fractures: modeling and analysis. J. Pet. Sci. Eng. 178, 640-648 (2019)

Cui, J., Sang, Q., Li, Y., Yin, C., Li, Y., Dong, M.: Liquid permeability of organic nanopores in shale: calculation and analysis. Fuel 202, 426-434 (2017)

Darabi, H., Ettehadtavakkol, A., Javadpour, F., Sepehrnoori, K.: Gas flow in ultra-tight shale strata. J. Fluid Mech. 710, 641-658 (2012)

de Gennes, P.-G.: On fluid/wall slippage. Langmuir 18(9), 3413-3414 (2002)

Doshi, D.A., Watkins, E.B., Israelachvili, J.N., Majewski, J.: Reduced water density at hydrophobic surfaces: effect of dissolved gases. Proc. Natl. Acad. Sci. 102(27), 9458-9462 (2005)

Elwinger, F., Pourmand, P., Furó, I.: Diffusive transport in pores. Tortuosity and molecular interaction with the pore wall. J. Phys. Chem. C 121(25), 13757-13764 (2017)

Ershov, A.P., Zorin, Z.M., Sobolev, V.D., Churaev, N.V.: Displacement of silicone oils from the hydrophobic surface by aqueous trisiloxane solutions. Colloid J. 63(3), 290-295 (2001)

Falk, K., Sedlmeier, F., Joly, L., Netz, R.R., Bocquet, L.: Molecular origin of fast water transport in carbon nanotube membranes: superlubricity versus curvature dependent friction. Nano Lett. 10(10), 40674073 (2010)

Fan, D.: Fluids transport in heterogeneous shale rocks. PhD thesis, Texas Tech University Lubbock, TX (2018)

Fan, D., Ettehadtavakkol, A.: Transient shale gas flow model. J. Nat. Gas Sci. Eng. 33, 1353-1363 (2016) 
Fan, D., Ettehadtavakkol, A.: Analytical model of gas transport in heterogeneous hydraulically-fractured organic-rich shale media. Fuel 207, 625-640 (2017a)

Fan, D., Ettehadtavakkol, A.: Semi-analytical modeling of shale gas flow through fractal induced fracture networks with microseismic data. Fuel 193, 444-459 (2017b)

Fan, H., Li, H., Wang, H.: Enhanced oil flow model coupling fractal roughness and heterogeneous wettability. Fractals 27, 1950088 (2019a)

Fan, D., Wang, W., Ettehadtavakkol, A., Su, Y.: Confinement facilitates wetting liquid slippage through mixed-wet and heterogeneous nanoporous shale rocks. In: Unconventional Resources Technology Conference (URTEC), Society of Petroleum Engineers. American Association of Petroleum Geologists. Society of Exploration Geophysicists (2019b)

Fan, D., Phan, A., Striolo, A.: Accurate permeability prediction in tight gas rocks via lattice boltzmann simulations with an improved boundary condition. J. Nat. Gas Sci. Eng. 73, 103049 (2020)

Farimani, A.B., Heiranian, M., Aluru, N.R.: Nano-electro-mechanical pump: giant pumping of water in carbon nanotubes. Sci. Rep. 6, 26211 (2016)

Feng, Q., Shiqian, X., Wang, S., Li, Y., Gao, F., Yajuan, X.: Apparent permeability model for shale oil with multiple mechanisms. J. Pet. Sci. Eng. 175, 814-827 (2019)

Ghanbarian, B., Javadpour, F.: Upscaling pore pressure-dependent gas permeability in shales. J. Geophys. Res. Solid Earth 122(4), 2541-2552 (2017)

Ghanbarian, B., Hunt, A.G., Ewing, R.P., Sahimi, M.: Tortuosity in porous media: a critical review. Soil Sci. Soc. Am. J. 77(5), 1461-1477 (2013)

Granick, S., Zhu, Y., Lee, H.: Slippery questions about complex fluids flowing past solids. Nat. Mater. 2(4), 221-227 (2003)

Hassenkam, T., Skovbjerg, L.L., Louise Svane Stipp, S.: Probing the intrinsically oil-wet surfaces of pores in North Sea chalk at subpore resolution. Proc. Natl. Acad. Sci. 106(15), 6071-6076 (2009)

Ho, T.A., Wang, Y.: Enhancement of oil flow in shale nanopores by manipulating friction and viscosity. Phys. Chem. Chem. Phys. 21(24), 12777-12786 (2019)

Ho, T.A., Papavassiliou, D.V., Lee, L.L., Striolo, A.: Liquid water can slip on a hydrophilic surface. Proc. Natl. Acad. Sci. 108(39), 16170-16175 (2011)

Hu, Y., Devegowda, D., Striolo, A., Phan, A., Ho, T.A., Civan, F., Sigal, R.F.: Microscopic dynamics of water and hydrocarbon in shale-kerogen pores of potentially mixed wettability. SPE J. 20(01), 112-124 (2014)

Hummer, G., Rasaiah, J.C., Noworyta, J.P.: Nanoscale hydrodynamics: enhanced flow in carbon nanotubes. Nature 414(6860), 188 (2001)

Janeček, J., Netz, R.R.: Interfacial water at hydrophobic and hydrophilic surfaces: depletion versus adsorption. Langmuir 23(16), 8417-8429 (2007)

Javadpour, F., Ettehadtavakkol, A.: Gas transport processes in shale. In: Rezaee, R. (ed.) Fundamentals of Gas Shale Reservoirs, pp. 245-266. Wiley, Hoboken (2015)

Javadpour, F., McClure, M., Naraghi, M.E.: Slip-corrected liquid permeability and its effect on hydraulic fracturing and fluid loss in shale. Fuel 160, 549-559 (2015)

Jensen, T.R., Jensen, M., Reitzel, N., Balashev, K., Peters, G.H., Kjaer, K., Bjørnholm, T.: Water in contact with extended hydrophobic surfaces: direct evidence of weak dewetting. Phys. Rev. Lett. 90(8), 086101 (2003)

Joseph, S., Aluru, N.R.: Why are carbon nanotubes fast transporters of water? Nano Lett. 8(2), 452-458 (2008)

Josh, M., Esteban, L., Piane, C.D., Sarout, J., Dewhurst, D.N., Clennell, M.B.: Laboratory characterisation of shale properties. J. Pet. Sci. Eng. 88, 107-124 (2012)

Kestin, J., Sengers, J.V., Kamgar-Parsi, B., Sengers, J.M.H.L.: Thermophysical properties of fluid $\mathrm{D}_{2} \mathrm{O}$. J. Phys. Chem. Ref. Data 13(2), 601-609 (1984)

Klinkenberg, L.J., et al.: The permeability of porous media to liquids and gases. In: Drilling and Production Practice, American Petroleum Institute (1941)

Kobayashi, K., Liang, Y., Amano, K., Murata, S., Matsuoka, T., Takahashi, S., Nishi, N., Sakka, T.: Molecular dynamics simulation of atomic force microscopy at the water-muscovite interface: hydration layer structure and force analysis. Langmuir 32(15), 3608-3616 (2016)

Lee, C., Choi, C.-H.: Structured surfaces for a giant liquid slip. Phys. Rev. Lett. 101(6), 064501 (2008)

Li, J., Kong, X., Diannan, L., Liu, Z.: Italicized carbon nanotube facilitating water transport: a molecular dynamics simulation. Sci. Bull. 60(18), 1580-1586 (2015)

Lu, J., Ruppel, S.C., Rowe, H.D.: Organic matter pores and oil generation in the Tuscaloosa marine shale. AAPG Bull. 99(2), 333-357 (2015)

Majumder, M., Chopra, N., Majumder, M., Chopra, N., Andrews, R., Hinds, B.J.: Nanoscale hydrodynamics: enhanced flow in carbon nanotubes. Nature 438(7064), 44-44 (2005) 
Mamatkulov, S.I., Khabibullaev, P.K., Netz, R.R.: Water at hydrophobic substrates: curvature, pressure, and temperature effects. Langmuir 20(11), 4756-4763 (2004)

Mattia, D., Calabrò, F.: Explaining high flow rate of water in carbon nanotubes via solid-liquid molecular interactions. Microfluid. Nanofluid. 13(1), 125-130 (2012)

Myers, T.G.: Why are slip lengths so large in carbon nanotubes? Microfluid. Nanofluid. 10(5), 11411145 (2011)

Naraghi, M.E., Javadpour, F.: A stochastic permeability model for the shale-gas systems. Int. J. Coal Geol. 140, 111-124 (2015)

Noy, A., Park, H.G., Fornasiero, F., Holt, J.K., Grigoropoulos, C.P., Bakajin, O.: Nanofluidics in carbon nanotubes. Nano Today 2(6), 22-29 (2007)

Podolska, N.I., Zhmakin, A.I.: Water flow in micro-and nanochannels. Molecular dynamics simulations. J. Phys. Conf. Ser. 461, 012034 (2013)

Qiu, T., Meng, X.W., Huang, J.P.: Nonstraight nanochannels transfer water faster than straight nanochannels. J. Phys. Chem. B 119(4), 1496-1502 (2015)

Rezaee, R.: Fundamentals of Gas Shale Reservoirs. Wiley, Hoboken (2015)

Secchi, E., Marbach, S., Niguès, A., Stein, D., Siria, A., Bocquet, L.: Massive radius-dependent flow slippage in carbon nanotubes. Nature 537(7619), 210-213 (2016)

Sendner, C., Horinek, D., Bocquet, L., Netz, R.R.: Interfacial water at hydrophobic and hydrophilic surfaces: slip, viscosity, and diffusion. Langmuir 25(18), 10768-10781 (2009)

Shaat, M.: Viscosity of water interfaces with hydrophobic nanopores: application to water flow in carbon nanotubes. Langmuir 33(44), 12814-12819 (2017)

Shen, L., Chen, Z.: Critical review of the impact of tortuosity on diffusion. Chem. Eng. Sci. 62(14), 3748-3755 (2007)

Song, F., Bo, L., Zhang, S., Sun, Y.: Nonlinear flow in low permeability reservoirs: modelling and experimental verification. Adv. Geo Energy Res. 3(1), 76-81 (2019)

Striolo, A.: The mechanism of water diffusion in narrow carbon nanotubes. Nano Lett. 6(4), 633-639 (2006)

Thomas, J.A., McGaughey, A.J.H.: Reassessing fast water transport through carbon nanotubes. Nano Lett. 8(9), 2788-2793 (2008)

Wang, Q., Cheng, Z.: A fractal model of water transport in shale reservoirs. Chem. Eng. Sci. 198, 62-73 (2019)

Wang, S., Feng, Q., Javadpour, F., Xia, T., Li, Z.: Oil adsorption in shale nanopores and its effect on recoverable oil-in-place. Int. J. Coal Geol. 147, 9-24 (2015)

Wang, S., Javadpour, F., Feng, Q.: Molecular dynamics simulations of oil transport through inorganic nanopores in shale. Fuel 171, 74-86 (2016)

Wang, S., Feng, Q., Zha, M., Javadpour, F., Qinhong, H.: Supercritical methane diffusion in shale nanopores: effects of pressure, mineral types, and moisture content. Energy Fuels 32(1), 169-180 (2018)

Wang, H., Yuliang, S., Zhao, Z., Wang, W., Sheng, G., Zhan, S.: Apparent permeability model for shale oil transport through elliptic nanopores considering wall-oil interaction. J. Pet. Sci. Eng. 176, 1041-1052 (2019a)

Wang, H., Yuliang, S., Wang, W., Sheng, G., Li, H., Zafar, A.: Enhanced water flow and apparent viscosity model considering wettability and shape effects. Fuel 253, 1351-1360 (2019b)

Wei, W., Cai, J., Xiangyun, H., Han, Q.: An electrical conductivity model for fractal porous media. Geophys. Res. Lett. 42(12), 4833-4840 (2015)

Whitby, M., Quirke, N.: Fluid flow in carbon nanotubes and nanopipes. Nat. Nanotechnol. 2(2), 87-94 (2007)

Whitby, M., Cagnon, L., Thanou, M., Quirke, N.: Enhanced fluid flow through nanoscale carbon pipes. Nano Lett. 8(9), 2632-2637 (2008)

Woodruff, W.F., Revil, A., Prasad, M., Torres-Verdín, C.: Measurements of elastic and electrical properties of an unconventional organic shale under differential loading. Geophysics 80(4), D363-D383 (2015)

Wu, L., Ho, M.T., Germanou, L., Gu, X.-J., Liu, C., Xu, K., Zhang, Y.: On the apparent permeability of porous media in rarefied gas flows. J. Fluid Mech. 822, 398-417 (2017)

Yang, S., Boming, Yu., Zou, M., Liang, M.: A fractal analysis of laminar flow resistance in roughened microchannels. Int. J. Heat Mass Transf. 77, 208-217 (2014)

Yang, Y., Yao, J., Wang, C., Gao, Y., Zhang, Q., An, S., Song, W.: New pore space characterization method of shale matrix formation by considering organic and inorganic pores. J. Nat. Gas Sci. Eng. 27, 496503 (2015a)

Yang, S., Liang, M., Boming, Y., Zou, M.: Permeability model for fractal porous media with rough surfaces. Microfluid. Nanofluid. 18(5-6), 1085-1093 (2015b) 
Yang, S., Dehghanpour, H., Binazadeh, M., Dong, P.: A molecular dynamics explanation for fast imbibition of oil in organic tight rocks. Fuel 190, 409-419 (2017)

Yang, Y., Wang, K., Zhang, L., Sun, H., Zhang, K., Ma, J.: Pore-scale simulation of shale oil flow based on pore network model. Fuel 251, 683-692 (2019)

Zhang, Q., Yuliang, S., Wang, W., Mingjing, L., Sheng, G.: Apparent permeability for liquid transport in nanopores of shale reservoirs: coupling flow enhancement and near wall flow. Int. J. Heat Mass Transf. 115, 224-234 (2017)

Zhang, W., Feng, Q., Wang, S., Xing, X.: Oil diffusion in shale nanopores: insight of molecular dynamics simulation. J. Mol. Liq. 290, 111183 (2019)

Zhao, S., Yaofeng, H., Xiaochen, Yu., Liu, Yu., Bai, Z.-S., Liu, H.: Surface wettability effect on fluid transport in nanoscale slit pores. AIChE J. 63(5), 1704-1714 (2017)

Zisman, W.A.: Relation of the equilibrium contact angle to liquid and solid constitution. Contact Angle, Wettability, and Adhesion, pp. 1-51. ACS Publications, Washington, D.C. (1964)

Publisher's Note Springer Nature remains neutral with regard to jurisdictional claims in published maps and institutional affiliations. 